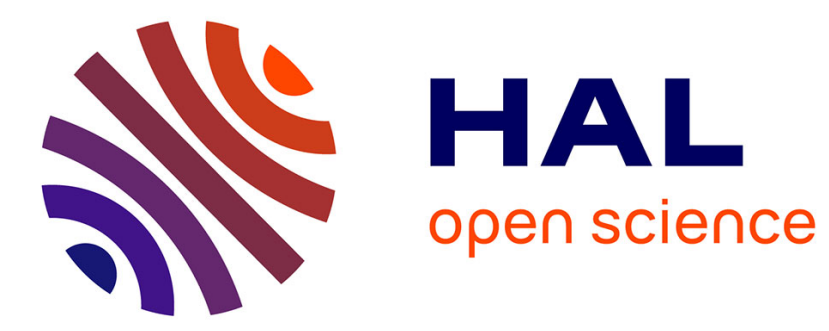

\title{
Investigating the Potential of Computer Environments for the Teaching and Learning of Functions: A Double Analysis from Two Research Traditions
}

Jean-Baptiste Lagrange, Giorgos Psycharis

\section{- To cite this version:}

Jean-Baptiste Lagrange, Giorgos Psycharis. Investigating the Potential of Computer Environments for the Teaching and Learning of Functions: A Double Analysis from Two Research Traditions. Technology, Knowledge and Learning, 2014, 19 (3), pp.255 - 286. 10.1007/s10758-013-9211-3 hal-01740459

\author{
HAL Id: hal-01740459 \\ https://hal.science/hal-01740459
}

Submitted on 22 Mar 2018

HAL is a multi-disciplinary open access archive for the deposit and dissemination of scientific research documents, whether they are published or not. The documents may come from teaching and research institutions in France or abroad, or from public or private research centers.
L'archive ouverte pluridisciplinaire HAL, est destinée au dépôt et à la diffusion de documents scientifiques de niveau recherche, publiés ou non, émanant des établissements d'enseignement et de recherche français ou étrangers, des laboratoires publics ou privés. 


\section{Investigating the Potential of Computer Environments for the Teaching and Learning of Functions: a Double Analysis from two Research Traditions ${ }^{1}$}

\section{Jean-Baptiste Lagrange • Giorgos Psycharis}

Abstract The general goal of this paper is to explore the potential of computer environments for the teaching and learning of functions. To address this, different theoretical frameworks and corresponding research traditions are available. In this study, we aim to network different frameworks by following a 'double analysis' method to analyse two empirical studies based on the use of computational environments offering integrated geometrical and algebraic representations. The studies took place in different national and didactic contexts and constitute cases of Constructionism and Theory of Didactical Situations. The analysis indicates that 'double analysis' resulted in a deepened and more balanced understanding about knowledge emerging from empirical studies as regards the nature of learning situations for functions with computers and the process of conceptualisation of functions by students. Main issues around the potential of computer environments for the teaching and learning of functions concern the use of integrated representations of functions linking geometry and algebra, the need to address epistemological and cognitive aspects of the constructed knowledge and the critical role of teachers in the design and evolution of students' activity. We also reflect on how the networking of theories influences theoretical advancement and the followed research approaches.

Keywords: digital technology, research tradition, networking of theoretical frameworks, functions, integrated representations, double analysis

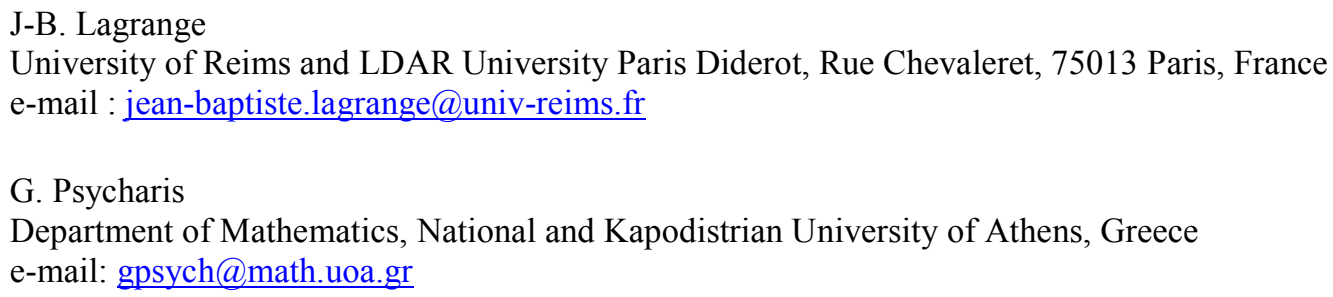

\footnotetext{
${ }^{1}$ Technology Knowledge and Learning. DOI 10.1007/s10758-013-9211-3. The final publication is available at www.springerlink.com.
} 


\section{Introduction}

The notion of function occupies a central role in a wide range of mathematical topics studied especially at the secondary and the upper secondary level. However, engaging students in functional thinking is known as a demanding task (Oehrtman et al. 2008). Existing research confirms students' difficulties in coordinating understandings in different settings (Bloch 2003) and dealing with representations in several registers (Duval 2000). Reform curriculum programs adopting a functional perspective to the teaching of algebra are usually oriented towards a less manipulation oriented algebraic content by promoting, with the use of technological tools, screen (graphical) interpretations of functions (Kieran 2007). Clearly, algebraic formalism seems to have been placed in the background of attention in these programs with the risk to deprive students from a direct access to symbolic forms of mathematical ideas. However, algebraic formalism is at the core of algebra and constitutes a powerful, inherently mathematical medium for expressing mathematical ideas. Recently, the development of new technological tools offering integrated representations of functions has generated further interest as regards their potential for the teaching and learning of functions. Yet, it seems difficult to really appreciate this potential, since it is needed to take into account the visions provided by specific theoretical frameworks, and because of the fragmented character of these frameworks (Artigue 2009).

Our overall research goal in this paper is to explore the potential of computational environments for the teaching and learning of functions. In order to address this goal, we seek to combat fragmentation by networking different theoretical frameworks. It is important to note that here we consider fragmentation as resulting from the existence of different research traditions. By research tradition, we do not mean only a reference to a theoretical framework, but also the research practices built jointly with a framework: reflection on a practice gives theoretical elements for a framework, and, in return, practice, that is to say design, observation and interpretation, is affected by the framework. Taking into account that a research tradition in the research on technology enhanced learning of mathematics can often be identified by a technology-based learning environment, a theoretical framework and a national educational and cultural context, we chose 
to consider two research traditions, both dealing with functions and software offering interconnected algebraic and geometrical representations, but different in many other aspects. One involves Turtleworlds, a piece of geometrical construction software combining dynamic manipulation of variable values with the symbolic notation provided by Logo programming. The design and the research on the use of Turtleworlds are inspired by Constructionism (Harel and Papert 1991) and have been carried out in the Greek context. The other research tradition involves Casyopée, a piece of software that offers a dynamic geometry window connected to a symbolic environment specifically designed to help students to work on functions. Casyopée's design and experimentations occurred in the French context that is shaped by didactical theoretical frameworks and epistemological considerations. We focus here on a framework preeminent in the French context -the Theory of Didactical Situations (TDS, Brousseau 1997), and on an epistemological typology of activity with functions built to make sense of the potential of computational environments with interconnected algebraic and geometrical representations (Lagrange and Artigue 2009).

Our choice to consider networking at the level of research traditions, lead us to question the research practices rooted in the above perspectives in terms of design, implementation and analysis of concrete research studies. Thus, we found it relevant to put each framework into action in producing a double analysis of teaching and learning phenomena that appear in two respective research studies focusing on functions, one with Turtleworlds and another one with Casyopée. In this approach, double analysis was seen by us as a means/tool to network the two frameworks by highlighting possible connections and divergent aspects and through this to address the potential of computer environments for the teaching and learning of functions. Therefore, the objectives guiding our research can be described in two levels. Firstly, we were interested in investigating the ways students' interactions with the provided representations may affect their opportunities for learning about function, according to each of the two theoretical frameworks. Taking into account the partial view provided by each framework, we wanted to provide a more complete analysis (supported by different theoretical and empirical components) of the same teaching and learning phenomena. This aim is addressed in Sections 4 and 5. Secondly, our aim was to discuss the potential of digital technologies for the teaching and learning of functions by 
linking double analysis to the existing literature. This aim is addressed in Section 6. As an agenda beyond the above aims, we expect to experience the profits and limitations of our networking attempt for theoretical advancement and development as well as for reflection on our own approaches.

In the next section, we outline the theoretical framework of this study. Then, the adopted methodology is sketched. Sections 4 and 5 contain a 'double analysis' of two empirical studies from a constructionist and TDS perspective, respectively. In Section 6, we discuss the potential of digital technologies for the teaching and learning of functions with respect to the concerns/issues raised by the double analysis. Finally, in Section 7 we present the conclusions of the article.

\section{Theoretical Framework}

In this section, we first outline the theoretical traditions at stake and particular theoretical tools and constructs through which each tradition considers the ways students conceptualise functions, namely situated abstraction and typology of activities for function. Then, we frame our approach to networking theoretical frameworks and describe the tools we used for this in the present study. Next, we provide a review of the existing literature concerning the role of computer environments as components of learning situations about functions. Finally, we summarise major trends identified by previous research as regards the processes of conceptualisation of the notion of function with computer environments.

\subsection{Constructionism and Situated Abstraction}

Constructionism incorporates and builds upon constructivism's connotation of learning as 'building knowledge structures' through progressive internalization of actions, in a context where students are consciously engaged in constructing (or de/re-constructing) physical and virtual models on the computer (e.g., geometrical figures, simulations, animations): the notion of construction refers both to the 'external' product of students' activity as well as to the process by which students come to develop more formal understandings of ideas and relationships (Papert 1980). The constructionist paradigm attributes special emphasis on students' construction of meanings when using mathematics to construct their own models during individual and collective 'bricolage' with digital artefacts, i.e. continual reshaping of digital artefacts by the students in order to complete specific tasks. It 
is important to note at this point that our interpretation of 'meaning' is not related purely to individual cognition but also to the way that students interact with digital artifacts and the social context of the classroom to appreciate explicitly mathematical relations and their semantics. In this perspective, a learning situation corresponds to a meaning generation process afforded by a conjunction of tinkering with digital representations, noticing feedback and communicating with others (teacher, other students). There is a dualistic nature of the idea: a learning situation indicates a process and a concrete object which represents the outcome of learner's activity in constructing something and communicating with others about it.

Under a constructionist perspective, Noss and Hoyles (1996) introduced the notion of situated abstraction to address how mathematical abstraction is scaffolded within computational media. They describe abstraction as a meaning generation process in which mathematical meanings are expressed as invariant relationships, but yet remain tied up within the conceptual web of resources provided by the available computational tool and the activity system. A critical point in this process concerns the potential of meanings to be transformed as students move the focus of their attention onto new objects and relationships within the setting, while maintaining their connections with existing ones. In this perspective, a 'situated abstraction' approach to students' conceptualisation of function within a particular computer-based setting involves meaning generation evident in the concretion of generalized relationships by students through the use of the available tools, linguistic conventions, and structures (e.g., expressed in the form of programmable code).

\subsection{TDS and Typology of Activities for Function}

Brousseau (1997) presents TDS as a model of learning by adaptation. The idea of situations is fundamental in TDS. It refers to a project organized (e.g., by the teacher) so as to cause one or some students to appropriate a certain piece of mathematical knowledge. 'Milieu', a coherent part of a situation, is defined as a system comprising material (e.g., tools) and non material (e.g., prior knowledge, symbols, interactions with other students) elements of a situation. Student's acting on the 'milieu' provokes feedback calling for modifying or adjusting action. Thus, 
the student is expected to create the targeted knowledge as response to the requirements of an 'antagonist' milieu rather than on the teacher's intentions. This is the a-didactical situation. Teaching has to organize the situation, in order to optimize the conditions of the interaction that is to say that progress in the interaction should be conditioned by a progress towards the knowledge aimed at in the situation. Thus, a learning situation in TDS involves a 'milieu' targeting a particular piece of mathematical knowledge and also an account of students' potential for learning through their interaction with the milieu. Such an account addresses progress in relation to an epistemological analysis of the targeted knowledge. By epistemological analysis, we mean an analysis situating a given knowledge in a scientific field, the different forms and expressions that it can take and its relationship with other knowledge.

The epistemological analysis favored in TDS situates functions at different levels (1) dependencies sensually experienced in a physical system (Radford 2005); dependencies between magnitudes, enhancing the consideration of functions as models of physical dependencies; (3) functions of one real variable, with formulas, graphs, tables and other possible algebraic representations. Based on the idea that students approach the notion of function by working on dependencies at these levels, Lagrange and Artigue (2009) proposed a typology of activities for functions. The typology connects the notion of function to the idea of covariation or dependency in physical systems (first level) where one can observe mutual variations of objects and also, at the second level, to the idea of input-output pairs of two magnitudes. It also distinguishes between types of representations and algebraic activities in each level. Particularly: iconic/enactive representations (Tall 1996); and three types of algebraic activities: generational (forming of expressions and equations), transformational (algebraic manipulation, e.g., factoring) and global/meta-level (not algebra-specific but related to the use of algebra, e.g., problem solving, modeling, looking for relationships) (Kieran 2007).

\subsection{Networking of Theories Representing Different Research Traditions}

At the level of their principles, Constructionism and TDS share a common focus on the design of learning through devices that provide affordances for interaction 
and knowledge construction. For instance, the idea of 'milieu', emerged and clearly defined within the TDS tradition, can also be seen by a constructionist perspective as a device - through not described with the same terms - that integrates teachers'/researchers' design of artifacts (e.g., tasks, microworlds) targeting rich meaning generation by the students. The divergence of the two perspectives is expected to become apparent if we consider the nature of design as activated in research practice. According to Radford (2008), there is space for further integrative attempts between the two traditions.

Networking different theoretical frameworks around the use of digital tools for the learning of mathematics is a current topic of research in the field (Drijvers et al. 2013). For achieving some integration amongst different traditions, BiknerAhsbahs and Prediger (2010) highlight the link between theory and research practice and adopt an approach "that conceptualizes theories in their dual character as frame and as a result of research practices" (ibid, p. 483). From a similar perspective, networking of theories in technology enhanced mathematics was addressed by six European research teams in the context of the project ReMath $^{2}$ through collaborative engagement in a 'cross-experimentation' programme leading to unified comparative accounts of pairs of studies of the same digital artifact (i.e. 'cross-case analyses') (Artigue 2009). ReMath indicated the importance of including the whole cycle of design-implementation-analysis of research studies in the networking process. This was the point of departure for our approach. Therefore, our initial step for networking was to address the need for mutual understanding by considering two research studies based upon the use of computer environments for the teaching and learning of function, each one designed and implemented within the corresponding research tradition.

Our next step in networking consists of producing a double analysis of concrete teaching and learning phenomena under the corresponding theoretical frameworks. As mentioned in the introduction, our first aim is to study how each tradition considers students' learning of function as well as to highlight possible connections and divergent aspects. At this point networking consists of comparing and contrasting the two approaches. The second aim of our study is to link the

2 "ReMath" (Representing Mathematics with Digital Media), 6th Framework Programme, Information Society Technologies, IST-4-26751-STP, 2005-2009 (http://remath.cti.gr). 
double analysis to the existing research concerning the use of computer environments for the teaching and learning of functions so as to shed light on what the double analysis may bring in the respective discussion in the field. In order to address this aim, we argue that the constituent elements of double analysis, i.e. the analyses carried out by each tradition, should be coordinated according to particular dimensions underlying research approaches as regards the design, implementation and analysis of learning situations for functions. Using different dimensions is seen by us as a way to make the divergence of the two perspectives come to the fore as well as to ensure a wider approach to the complex classroom reality. For instance, as evidenced in Section 2, "what a learning situation is' should be answered differently by a constructionist perspective and TDS. Both traditions emphasize design in some sense, but Constructionism emphasizes rich meaning generation through construction activities without precisely foresee students' procedures, while TDS gives priority to the development of an epistemological analysis of the aimed mathematical knowledge as a means to ensure that students' interaction will actually put this knowledge at stake. This brings us to our last step in networking which consists of coordinating (Prediger et al. 2008; Bikner-Ahsbahs and Prediger 2010) Constructionism and TDS by coordinating the respective analyses in terms of two dimensions: 'Economy of learning situations' and 'Conceptualisation of function'.

The notion of 'economy' of learning situations has been used by Hoyles, Lagrange and Noss (2006) in order to describe better the role of many different components intervening in the classroom progression of knowledge: students, teacher, but also various artefacts, some of these material (e.g., blackboard, disposition of the room) and the others non material (e.g., tasks, rules, systems of notation, language). Although the term 'situations' refers to the work of Brousseau, the authors adopted it without any didactic theorization. They define the economy of a learning situation as a specific organization of the classroom components (i.e. actors and artefacts), which encompass activities, interactions and norms within the classroom, and suggest that "technology brings changes and specificities in this economy" (ibid, p. 301) leading to a kind of 'perturbation' in the classroom. Aspects of context are challenged, actors take different roles than their 'usual' ones (e.g., the changing role of the teacher in the classroom), students' mathematical activity is shaped by the use of particular technological 
tools, new kinds of meanings are generated. It should be interesting, in our case, to investigate the contribution of the two research traditions to this important dimension of learning situations in the double analysis.

The second dimension refers to the students' construction of knowledge when learning about functions. The constructionist approach in this study is influenced by situated abstraction, while the TDS approach relies upon the typology of activities for functions. Thus, the corresponding analyses are expected to bring to the fore a cognitive/epistemological duality in approaching students' learning for functions.

\subsection{Functions in Computational Environments: The Economy of Learning Situations}

A first motivation is in the computer's potential for integrating a multiplicity of representations such as symbolic (algebraic), coordinate graphical, tabular, and iconic. Kieran and Yerushalmy (2004) review a variety of software taking advantage of this multiplicity and note that "intensive use of multiple representations technology (often) define themselves as functional approaches" (ibid., p. 103) and that "educators seek tools that will allow students to mathematically represent personal experiences as functions" (ibid., p. 105).

As Kieran and Yerushalmy (ibid, p. 120) point out, dynamic control, that is to say direct manipulation of representation, often complements multiple representations of functions. With regard to algebraic representations, devices like sliders or dragging modalities allow direct control of algebraic expressions, for instance by animating parameters, or manipulating graphs. Also specially designed applets provide additional opportunities for interaction with algebraic representations through construction and use of chains or operations (e.g., arrow chains) and options for scrolling and tracing. For instance, such an applet (called AlgebraArrows) fostered students' covariation understanding of functions through construction and modification of arrow chains (Doorman et al. 2012). With regard to non algebraic representations, authors who work with environments offering multiple interconnected representations stress the crucial role that the use of these representations can play in promoting students' understanding of functional dependencies. For instance, part of research with Dynamic Geometry Systems 
(DGS) concerns students' conceptualisation of covariation when dragging certain geometrical objects in a continuous manner and observing how dependent geometrical constructions responded to this (Hazzan and Goldenberg 1997; Falcade et al. 2007). Authors who address the economy of learning situations in dynamic environments do so by way of a framework in the research tradition they participate in (see for instance Theory of Semiotic Mediation in the research study by Falcade et al. ibid.).

Computer programming is an alternative way of building and manipulating representations, and a motivation for researchers: writing procedures in a specific language allows the construction of functions providing rich experience with the notion of function as process possibly 'encapsulated' in objects (Dubinsky 1999). Programming can also be seen as means to provide a representational infrastructure alternative to traditional symbolism, thus making the idea of formalized functional dependency more learnable for students (Noss 2004). The constructionist perspective has been built to make sense of situations involving programming as means to access mathematical ideas.

A substantial body of research also exists at upper secondary level about the use of Computer Algebra Systems (CAS) (Thomas et al. 2004). As a difference with research on multirepresentational dynamic tools, research on CAS does not generally focus on functions, but rather on more general algebraic ideas. For instance, Kieran and Drijvers (2006) insist on the role that CAS can play for supporting the understanding of algebraic equivalence and forms. Lagrange (2005) and Weigand and Bichler (2010) represent a shift towards using CAS embedded into environments allowing exploration of algebraic functions. The complexity of CAS environments and the problematic classroom integration explain why a big part of research studies about CAS use deals with questions of classroom efficiency. These studies bring concerns about the economy of learning situations often not addressed by research based on the use of other kinds of computer environments (Artigue 1997).

More recently, computer environments offering both geometrical and algebraic capabilities have been designed with the aim of providing some sort of combination of DGS and algebraic multirepresentation, possibly including CAS and/or spreadsheet (Mackrell 2011). The need to explore the transformative 
potential of the corresponding technologies has been related to the fact that such systems could encourage different levels of interplay between the two powerful mathematical worlds, different kinds of algebraic expression as well as new opportunities for direct manipulation of dynamically linked geometric and symbolic forms of mathematical objects. In addition, most up-to-date computer environments allow the user to animate objects by way of a programming language, providing alternative representational systems and reintroducing design ideas reviewed above.

The assumptions underpinning the development of these environments are very diverse. Designers stress the possibility for students to make the connection between various representations in analytic geometry, for instance a figure and its Cartesian equation, and the affordances for users to 'act' on these connected representations. "It is possible to investigate the parameters of a circle's equation by dragging the circle with the mouse. On the other hand, students may also manipulate the equation directly and see the changed circle in the geometry window." (Hohenwarter and Fuchs 2005). The nature of tasks associated with these environments in learning situations (for instance optimization) puts the notion of function often at stake. Researchers insist on the possibility for students to solve tasks in various environments offering interconnected representations (e.g., DGS, CAS, spreadsheet), and also on the complexity of these environments that might be a problem for teachers (Artigue and Bardini 2010), converging with the concern for the economy of learning situations raised by research about CAS.

\subsection{Conceptualising the Notion of Function with the Help of Computers}

\subsubsection{From Process-Object to Covariation Aspect of Functions}

From early nineties most of the studies concerning students' conception of functions were based on the distinction between the two major stances that students adopt towards functions: the process view and the object view (Kieran 1992; Sfard 1991). The process view of functions is characterised by students' focus on the performance of computational actions following a sequence of operations (i.e. computing values) while the object view is based on the 
generalisation of the dependency relationships between input-output pairs of two quantities/magnitudes (Breidenbach et al. 1992).

Elaborating further the process-object duality in students' understanding of functions, mathematics educators suggested that students' understanding of functions can be considered as moving from an initial focus on actions and processes to more object-oriented views characterized by a gradual focus on structure, incorporation of properties and reification of mathematical objects (Breidenbach et al. 1992). In this vein, from the middle nineties, a number of approaches developed to describe object-oriented views of function emphasized the covariation aspect of function (Thompson 1994; Confrey and Smith 1995; Carlson et al. 2002; Oehrtman et al. 2008). The essence of a covariation view is related to the understanding of the manner in which dependent and independent variables change as well as the coordination between these changes. According to Carlson et al. (2002) covariational reasoning consists of "the cognitive activities involved in coordinating two varying quantities while attending to the ways in which they change in relation to each other." (ibid., p. 357). However, this dynamic conception of variation seems to be not obvious for the students since it is essential to take into account simultaneously variation between magnitudes in different levels emerging in an ordered succession, and there is a need for situations that provide students with opportunities to think about the covariational nature of functions in modeling dynamic events.

\subsubsection{Understanding the Idea of Independent Variable}

A particular difficulty in understanding functions deals with the idea of independent variable. Using Tall and Vinner (1981) notion of concept image and concept definition, Thompson (1994) reports students' persistent “mal-formed concept images (...) showing up in the strangest places" (ibid, p. 6). He particularly indicates that the predominant image evoked for students by the word 'function' involves two disconnected/separated expressions linked by the equal sign. Aiming to indicate students' difficulty to develop a conceptual understanding of the symbolic expression of functional relations and the role of particular symbols in it, he reports an example of a formula for the sum $S_{n}=1^{2}+2^{2}+\ldots+n^{2}$ given by a student on the blackboard as a response to the 
teacher's request. The student wrote $f(x)=\frac{n(n+1)(2 n+1)}{6}$ and none of the students found something wrong with this expression since it seemed to fit their image of function at that time. Here the student's use of symbols for the expression of a functional relation indicates an implicit consideration of it as a 'template' consisting of two distinct parts in which the first one is used as a label for the second without linking at the conceptual level these two parts and the existing objects/quantities.

\subsubsection{The Role of Symbolism}

Connecting the symbolism of functions with the above aspects is also a major difficulty for students. Students' view of symbolic expressions can be of a pure input-output correspondence. In other circumstances, it can be pseudo-structural, the expressions being understood as an object in itself, not connected to functional understanding (Sfard 1991). Slavit (1997) indicates the critical role of symbolism "confronted in very different forms (such as graphs and equations)" (ibid, p. 277) in the development of the function concept and suggests the need for students' investigation of algebraic and functional ideas in different contexts such as the geometric one. Even when students have access to basic proficiencies in algebraic symbolism, coordinating these proficiencies with an understanding of the structure of the algebraic formula in a function is critical and is particularly at stake when the function comes from a problem context. Most students fail in this coordination. Evidence of failure is given in the context of equation. For instance, van der Kooij (2010) notes that most students in a vocational high school were able to do calculation on the pendulum equation $T=2 \pi \sqrt{\frac{l}{g}}$ while they gave no sense to an 'abstract' equation like $y=2 \sqrt{x}$. Kieran (2007) reports on low achievement across countries for items of a TIMSS survey involving production or interpretation of formulas to describe a phenomenon depending on a variable number.

\section{Methodology}

The authors of this paper consist of one researcher who is experienced in using TDS in his research (the first author) and one researcher who has a substantial 
experience in working under a constructionist perspective (the second author). Both of them participated in the project ReMath as members of two research teams. The experience of the two teams in cross-analysing the same experiment under TDS and constructionist lens brought evidence that divergent views of functions as well as distinct theoretical orientations can produce a lot of misunderstandings relatively to design and possible uses of a tool, to students' activity and to the notion of function as implemented in a tool. Our method in this study is inspired by our experience in ReMath. However, here it goes further in terms of networking, since our aim is to provide a coordinated analysis of different research studies as a means to tackle the potential of computational environments for the teaching and learning of functions.

We chose two experiments to be representative of the research practices in the two traditions but also very distinct. We mentioned in the introduction the specificities of each software that make them very different. The contexts of use were also very different in the two studies, the Casyopée study being for 11th grade students in scientific stream in the French context, while the Turtleworlds study was for 7th grade mixed-ability classes in the Greek context. This diversity was chosen in order to get a broad view of the teaching and learning of functions, going beyond the particularities of a school level or other contextual factors. The fact that the data of each study stem from research work carried out by the two authors separately, was a challenge for us to share as much information on the design and implementation in each case (e.g., educational context, method). The overall description of the design of each study and the reported episodes in Sections 4 and 5 were written by the respective authors.

As a next step, we were engaged in identifying dimensions for analysing data from the classroom in order to be able to coordinate our own approaches. Due to our common focus on the learning of function, 'conceptualisation of function' was one obvious dimension for both of us. Also, taking into account our ReMath experience, we saw the need for a dimension addressing at a more general level how each research tradition considers classroom as a system of interrelated components (e.g., subjects, tools, activities) which affects the construction and progression of knowledge. Joint reflection lead us to adopt the notion of 'Economy of learning situations' presented above. After this, we prepared a 
review of the literature about functions in computer environments according to the chosen dimensions (see Sections 2.4 and 2.5). In Section 6, this choice will be prove to be useful in our attempt to situate the results of the present study in the existing research in the field.

Next, each of us wrote an outline on the Constructionism and TDS framework respectively, explaining also the core elements of our lenses in order to address the two dimensions (e.g., how a 'learning situation' may be conceived in each framework). These outlines were the base of the theoretical perspectives we described earlier in Sections 2.1 and 2.2. Then, each of us worked separately from the other for carrying out the analysis of a particular piece of data from his own experiment (e.g., an episode) according to the dimensions mentioned above. Particularly, we agreed to analyse data in which key aspects of functions were brought to the fore through students' use of the available tools as well as to provide as much information on the context of students' activity.

Next, we exchanged these ('original') analyses with the detailed description of each study (aims, method, etc.) and we started a process of making understandable one's own approach which involved discussion and joint reflection on the 'original' analyses. In the end of this process, each one of us was able to react on the study and the analysis of the other's under his own ('alien') perspective. This way two second analyses were produced. For more opportunities for comparing and contrasting our approaches, we decided these second analyses to be written in terms of concerns/issues brought by the 'alien' tradition to the original analysis. In subsequent in person meetings, we worked collaboratively to clarify these analyses for more accessible descriptions of the findings according to claims and assumptions of the two frameworks. We note that the use of 'we' and 'our' in the constructionist and TDS analyses (i.e. Sections 4 and 5) refers to each one of us considered as a member of the respective community of (constructionist/TDS) researchers. In any other part of the paper the use of 'we' and 'our' signifies our common ground of interpretation built through our collaborative work by the end of the reported study.

Finally, the process of coordinating the two approaches in terms of the chosen dimensions and the making of links with the existing literature was carried out in close but mainly distant collaboration (see Section 6). This process involved also 
comparing and contrasting the two approaches taking into account the concerns/issues brought mainly by the 'alien' analyses mentioned above. Conclusions on the central aim of the study and on the outcomes of double analysis were also drawn. Overall, this process took nearly two years.

\section{Turtleworlds study}

\subsection{Aims and Choices}

This central research question in this study concerned how a computer environment offering integrated representations could help students to understand dependencies and express them in formal notation. The study was designed from a constructionist inspiration and then the choice was to favor students' meaningful engagement in a purposeful task: enlarging-shrinking geometrical figures. As regards the notion of function, this task presents a potential for identifying a mutual dependence between two comparable quantities (interdependency), and also a potential for distinguishing certain kinds of dependence (e.g., additive, multiplicative) between two comparable quantities: proportional relations are considered as means to concretize relationship between measures in the geometric enlargement context. The functionalities of the computer environment were chosen in order to prompt students to construct relationships and figures according to the rules of proportionality. These rules were not initially explicit to the students, the aim being to emerge through interaction with the available tools: the environment was expected to provide feedback leading to visually-based cognitive conflict, particularly when using additive strategies. The need of a computer environment that allows formal expression of relationships was critical.

Turtleworlds (Kynigos 2004) consists of three interconnected components: Canvas, Logo and Variation Tool. The elements of a geometrical construction can be expressed in a Logo procedure with the use of variables or functional relationships including variables. The user is able to dynamically manipulate the geometrical figure by dragging specific pointers along the 'number line'-like representation of these variables using the dynamic manipulation feature of the computer environment called 'variation tool'. After a procedure depending on variables is defined and executed with a specific value, clicking the mouse on the 
turtle trace activates the variation tool, which provides a slider for each variable. For instance, the procedure 'letterN' (Fig. 1) creates a model of the letter 'N' with two variables representing the vertical segments and the 'tilted' segment respectively. The dragging of a slider results in a continual reshaping of the figure according to the corresponding variable value (Fig. 1).

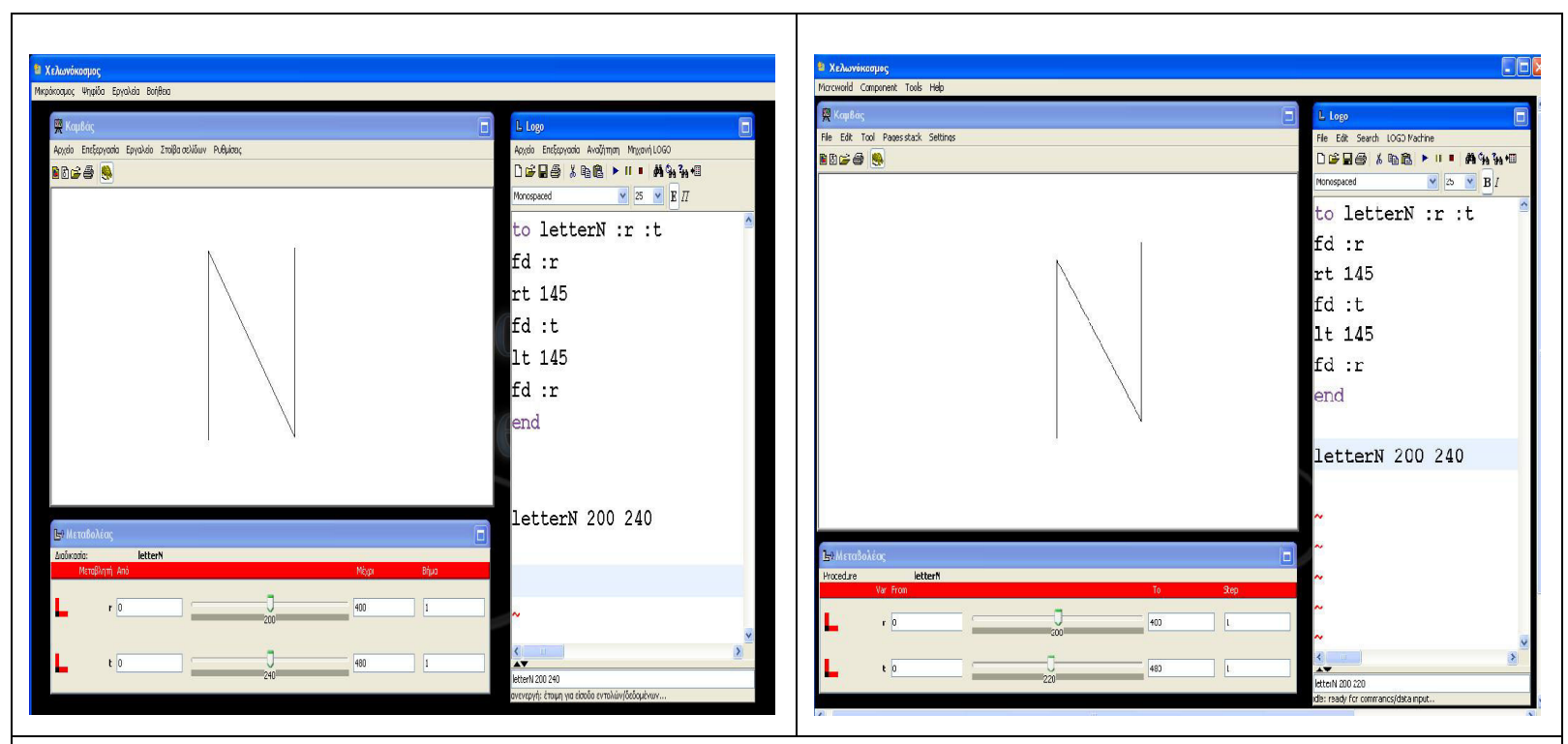

Fig. 1. A model of "N" with two variables and internal angle $35^{\circ}$. The values on the two sliders are: $r=200$ and $t=240$ (left). Dragging the slider $: t$ to the value 220 leads to the figure on the right.

\subsection{Task}

The task called Dynamic Alphabet was designed to engage purposefully a class in constructing enlarging-shrinking models of all the capital letters (i.e. of variable sizes) with one variable corresponding to the height of the respective letter. Moving the slider of the variation tool in this case would result in the visualisation of the letter as an enlarging-shrinking geometrical figure. Thus, the students had to chose an independent variable and express all the varying lengths of each letter procedure with appropriate functional relationships. For enlarging-shrinking the fixed model of ' $N$ ' shown in Fig. 1, the students had to consider :r as independent variable and express variable :t as $1.2 *(: r)$. Students, however, were simply asked to design letters having the same height, as if they were designed between two lines of a note book. The research aim was to see if and how students might come to 'translate' these constraints in formal mathematical notation through their interaction with the available tools. Since, the inclusion of an additive relationship in a procedure would result in a 'distorted' figure for different values in the 
variation tool, the students were expected to identify a general 'method' to prevent distortions and through this to recognize the utility of mathematical ideas.

\subsection{Context and Data}

The experiment with Turtleworlds took place in a secondary school in Athens, Greece with two 7 th grade mixed-ability classes (first grade of the secondary level) with 26 13-year-old students in each class and two mathematics teachers. Each class had only one teacher. Classroom implementation was carried out in 16 teaching sessions for each class - 2 sessions per week - with the participating teachers over two months. Arrangements were made for the research to take place before the concepts of shrinking and enlarging geometrical figures were officially introduced to the students. This was done in order to avoid students' attempts to reproduce taught methods and algorithms and, also, in order to enhance the exploratory potential of their engagement with the task. The students had also had some experience with traditional Logo constructions, including variable procedures. In each session the second author participated as participant observer in the classroom and intervened more or less assuming the role of a teacher, by posing questions, encouraging students to explain their ideas and strategies and asking for refinement and revision when appropriate.

Through the use of two video-cameras, video recordings were collected by one group of students in each class (focus groups) and the overall classroom activity. The focus groups - which were the same in all sessions - consisted of students whose ability in mathematics had been reported by the teachers as average. Additionally, these students were familiar in working together and they were open in talking to the researcher/teacher about their thinking and strategies. During data collection one camera and one wired microphone were on the focus groups. Our intention was to capture the evolution of focus groups students' activity (e.g., strategies, use of tools) throughout the teaching sequence. Through the second camera we recorded the overall classroom activity as well as interesting interactions in student groups other than the focus group.

\subsection{The Work of Alexia and Christina}

Early in their work most of the students constructed a model of their letter - called as original pattern in the study - sometimes without using any variables. In 
subsequent phases of their exploration, students experimented with the use of variables for all of its segments, to change it proportionally, until they built their final model with one variable. Here the focus is on a pair of students - Alexia and Christina (focus group, Class A2) - exploring the construction of an enlargingshrinking model of the letter $\mathrm{N}$ that they completed in six successive phases during four classroom sessions. Below, there is a brief description of students' activities in each phase.

\begin{tabular}{|c|c|c|}
\hline to letterN & to letterN & to letterN :r :t \\
\hline fd 200 & fd 100 & fd $: r$ \\
\hline rt 145 & rt 135 & rt 145 \\
\hline fd 240 & fd 145 & $\mathrm{fd}: \mathrm{t}$ \\
\hline lt 145 & lt 135 & lt 145 \\
\hline fd 200 & fd 100 & $\mathrm{fd}: \mathrm{r}$ \\
\hline end & end & end \\
\hline \multicolumn{2}{|c|}{ Phase 1} & Phase 2 \\
\hline to letterN :r & to letterN :r & to letterN :r \\
\hline $\mathrm{fd}: \mathrm{r}$ & $\mathrm{fd}: \mathrm{r}$ & $\mathrm{fd}: \mathrm{r}$ \\
\hline rt 145 & rt 145 & rt 145 \\
\hline $\mathrm{fd}: \mathrm{r}+40$ & $\mathrm{fd}: \mathrm{r}+50$ & $\mathrm{fd}: \mathrm{r}+45$ \\
\hline lt 145 & lt 145 & lt 145 \\
\hline $\mathrm{fd}: \mathrm{r}$ & $\mathrm{fd}: \mathrm{r}$ & $\mathrm{fd}: \mathrm{r}$ \\
\hline end & end & end \\
\hline \multicolumn{3}{|c|}{ Phase 3} \\
\hline to letterN :r & to letterN :r & to letterN :r \\
\hline $\mathrm{fd}: \mathrm{r}$ & $\mathrm{fd}: \mathrm{r}$ & $\mathrm{fd}: \mathrm{r}$ \\
\hline rt 135 & rt 135 & rt 135 \\
\hline $\mathrm{fd}: \mathrm{r} * 1.5$ & $\mathrm{fd}: \mathrm{r}^{*} 1.45$ & $\mathrm{fd}: \mathrm{r}^{*} 1.42$ \\
\hline lt 135 & lt 135 & lt 135 \\
\hline $\mathrm{fd}: \mathrm{r}$ & $\mathrm{fd}: \mathrm{r}$ & $\mathrm{fd}: \mathrm{r}$ \\
\hline end & end & end \\
\hline \multicolumn{2}{|c|}{ Phase 4} & Phase 5 \\
\hline
\end{tabular}

Table 1: The Logo codes of $\mathrm{N}$ in the first five phases of students' work.

Phase 1: Construction of the original pattern of $\mathrm{N}\left(35^{\circ}\right)$ (vertical segments $=200$, slanted segment $=240$, internal angle $\left.=35^{\circ}\right)$ and $N\left(45^{\circ}\right)$ (vertical segments $=100$, slanted segment $=145$, internal angle $=45^{\circ}$ ). 
Phase 2: $\mathrm{N}\left(35^{\circ}\right)$ construction with two variables for the vertical segments and the slanted segment respectively. Recognition of the interdependence of variables. Exploration of the construction of similar $\mathrm{N}\left(35^{\circ}\right)$ models of different sizes.

Phase 3: $\mathrm{N}\left(35^{\circ}\right)$ construction with one variable and specification of an additive functional relation between the vertical segment and the slanted segment. Experimentation with changes to the constant value of the additive functional relation used to represent the slanted segment.

Phase 4: $\mathrm{N}\left(45^{\circ}\right)$ construction with one variable and specification of a multiplicative functional relation between the vertical segment and the slanted segment (not appropriate function operator). Experimentation with changes to the constant value of the function operator used to represent the slanted segment.

Phase 5: $\mathrm{N}\left(45^{\circ}\right)$ construction with one variable and appropriate multiplicative functional relation between the vertical segment and the slanted segment.

Phase 6: Exploration of the construction of different models of $\mathrm{N}\left(25^{\circ}, 30^{\circ}, 35^{\circ}\right.$, $45^{\circ}$ ) and specification of appropriate multiplicative functional relations.

The examples the group's work presented below were chosen so as to highlight critical aspects of the students' transition from the additive to the multiplicative approach to the problem at hand.

\subsubsection{From phase 2 to phase 3: Emergence and Evolution of Additive Strategies}

During phase 2, students were engaged in constructing different models of $\mathrm{N}\left(35^{\circ}\right)$ by successive dragging on the two sliders of the variation tool (:r and :t) (see Table 1). They tested the procedure for different values of :r and on the basis of the screen outcome adjusted the input of the second variable. Then the students were challenged to consider the co-variation of the two variables (:r and :t) for constructing an enlarging-shrinking similar models of $\mathrm{N}\left(35^{\circ}\right)$ in different sizes. Initially, they considered the relation of the two values as "200 plus forward 40" which they used in the construction of the respective original pattern of $\mathrm{N}\left(35^{\circ}\right)$. Thus, they substituted variable :t with the functional expression (:r+40). When Alexia moved the slider :r to the value 220, the figure was distorted (see Fig. 1) and Christina conjectured directly for the changes in the functional expression 
("we need to add 50"). This way students continued to work with additive relations (e.g., :r+50, :r+45) but moved from constant differences to adjusted differences according to the different values of the independent variable. Meaning generation in this phase was further enriched by students' engagement in specifying sub-domains for the values of the independent variable (i.e. "between 195 to 205") for which figure distortion seemed to be minimised on the screen for different additive relations. However, successive dragging on the variation tool confirmed that the use of an additive algebraic expression constituted an erroneous strategy for constructing an enlarging-shrinking model of $\mathrm{N}$ holding for "all values of :r".

\subsubsection{From phase 3 to phase 4: Emergence and Evolution of Multiplicative} Strategies

The students moved to the multiplicative strategies in the subsequent construction of an enlarging-shrinking model of $\mathrm{N}\left(45^{\circ}\right)$ as they started to rethink the functional relation between the two varying magnitudes and its expression in the Logo code. In the next excerpt (the students discuss about the identification of an appropriate functional relation for the slanted length so as to construct an enlarging-shrinking model of $\mathrm{N}\left(45^{\circ}\right)$ (vertical segments $=100$, slanted segment $=145$ in the original pattern).

Researcher: Since the one [i.e. the vertical segment] is 100 and the other one [i.e. the slanted segment]. What is the relation between 145 and 100 ?

Christina: It [i.e. the slanted length] is neither half. It is half ... let's say plus 45.

Researcher: Half?

Christina: Not exactly. [After a while] One and 45 which we have already put here [i.e. the expression : $r+45]$. Oh, it is half ... 45. Half.

Alexia: One and ...

Christina: One and ... Yes, one and a half.

Christina seems to attempt to move back and fourth move between additive (i.e. plus 45) and multiplicative (i.e. one and a half) forms of the relation between the two lengths. In her last quoted phrase, she describes verbally a functional relation but seems to be reluctant to express it through symbolic language in the code. At that point the researcher modified the focal point of his question to include the covariation of the two lengths and asked the students directly what kind of relation they suggested for the slanted length in relation to the vertical one. 
Researcher: If this is one time and half bigger than the tilted one. How much is it?

Alexia: :r plus one and a half.

Christina: [to Alexia] No, it would be two times and a half then. It's :r plus half. It is one time and half bigger.

Alexia: :r plus half.

Christina: [Thinks for a while] :r times one and a half. Lets' try it [Christina then goes straight to the Logo editor and types the linear relation as $1.5 *:$ for the slanted length.]

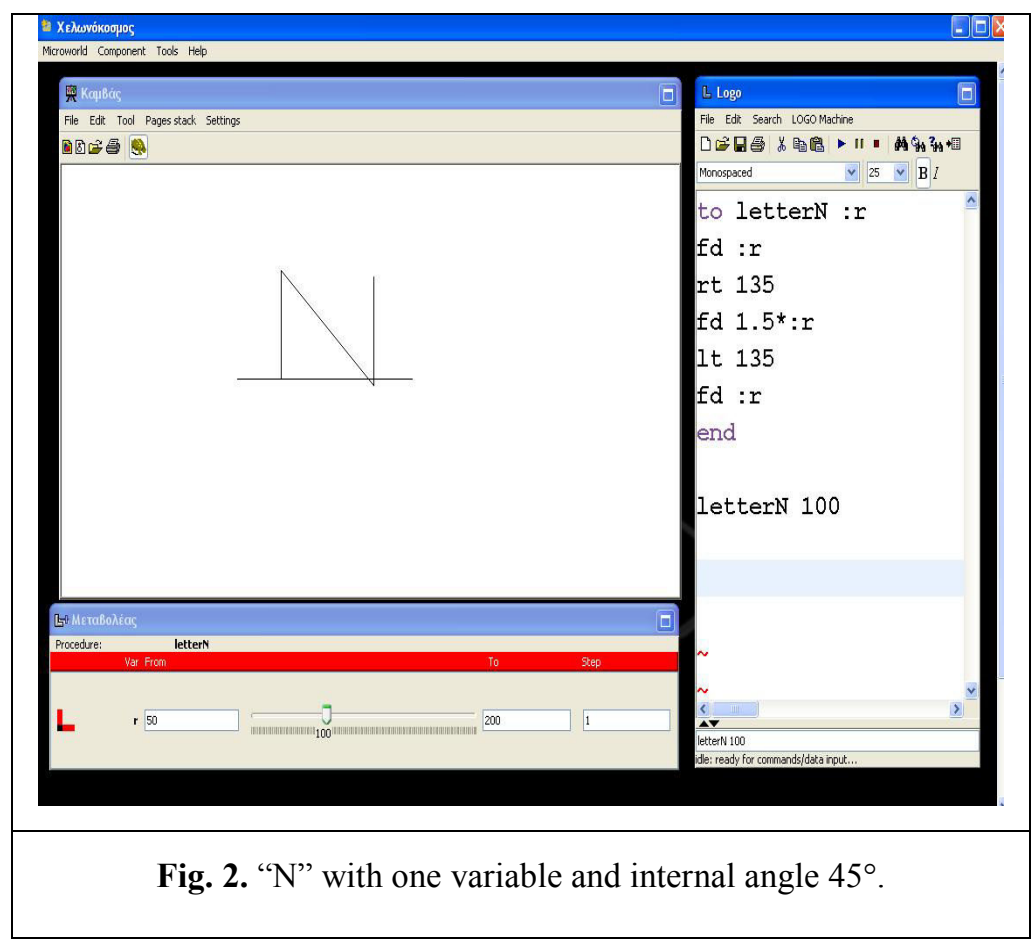

The multiplicative expression 1.5*:r (Fig. 2) seemed to have emerged as a synthesis between Christina's sense of the distributive property with the multiplication of a variable with a decimal number, i.e. $: \mathrm{r}+1 / 2 *(: \mathrm{r})=1.5 *(: \mathrm{r})$. Using this relation as a basis, these students were engaged in 'correcting' distortions to figural representations resulting from the symbolic code. This process was characterized by their gradual refinement of the relationships employed in accomplishing the enlarging-shrinking geometrical construction. After experimentation with changing the values of the functional operator they accepted as value 1.42 which actually is an approximation of the real value of the functional operator calculated through trigonometry. It is important to note that the students had drawn a line at the letter base so as to precisely evaluate the accuracy of their approximations for the functional operator (see Fig. 2). 


\subsection{Analysis from the Constructionist Perspective}

\subsubsection{The Economy of the Learning Situation from the Constructionist Perspective}

From a constructionist point of view, the sequence of the above episodes brings to the foreground two critical aspects of the construction of geometrical figures according to proportionality: first, how the students can appreciate the inappropriateness of additive strategies and, second, how they can identify and express multiplicative functional relations in formal notation. A critical step in this direction is the translation of the dependency between the vertical and the slanted side in symbolic notation through a process in which values, variables and everyday language are simultaneously interlinked. Although the relation between the two magnitudes/lengths can be initially perceived by the students as additive, the computational environment provides a structure which students can use to express the corresponding function, tools for experimenting with it and further elaborating its formula. At the same time students have opportunities to relate specific numerical values of two variables and after considering one variable as an independent one to determine the values of the dependent variable given the value of the independent one and identify and express a functional relationship between the two based on the analysis of the data available through their exploration. Thus, the students can move from identifying dependence and co-variation between magnitudes to identifying and expressing co-variation between magnitudes represented through variables.

This is considered as a critical step in the evolution of students' activity since it represents a shift in students' attention from the variation between values of variables to the simultaneous covariation (though initially perceived as additive) of the two lengths. At the same time, the students can create links between the functional relation corresponding to the side length and particular domains of variation of the independent variable. From a constructionist perspective, we see that the generated meanings can be reshaped as the students move the focus of their attention onto a relation which is a new object within the setting. 


\subsubsection{The Process of Conceptualisation from the Constructionist Perspective}

The chain of meanings for function here involves (a) the idea of variable as representing a general entity that can assume any value and symbolise general rules, (b) the specification of domains of validity for an additive functional relation and the development of methods to take control of the distortion of the figure (e.g., design of straight line in the letter base), (c) experimentation with the symbolic form of the additive functional relation and (d) implications of the potential emergence of the multiplicative functional relation between the two variables representing the vertical and the slanted side. The chain of meanings seems to be reshaped through the use of the variation tool. The abnormality of the graphical outcome leads students to use the tool in such a way that dragging, in conjunction with the symbolic notation, helps them to extend the elaboration of the proportional relation between the covarying magnitudes so as to prevent the distortion of the shape.

We consider the selected excerpts in the above paragraph as illustrative examples of the dynamic nature of the functional meanings developed by the students. The researcher's remark about the relation between two specific numerical values triggers students' focus on the functional relation between the two corresponding lengths. Christina seems to be able to articulate the dependent length as situated abstraction with direct reference to the independent variable :r. In contrast, we see that Alexia seems to describe the emergent relations under an additive rather than a multiplicative approach since she always refers to addition (indicated by the use of the word 'plus') without providing a clear description of the inherent functional relation. Although it is not clear what is the symbolic form of the functional relation suggested by Christina in the first excerpt - i.e. $(: r+: r / 2)$ or $(1+: r / 2)$ or $(1+: r) / 2$ - the available symbolic component of the environment allows students to test these relations, thus providing a basis for further elaboration based on the use of the variation tool and the graphical feedback. In the end of the second excerpt Christina's transition to a multiplicative functional relation is indicated by the use of the word 'times'. Thus, she seems to link in a relevant way the expression ': $r$ plus half' (of :r) emerging through interaction with the tool with the expression ':r times one and a half' based on her knowledge of the distributive property. In 
summary, the following situated abstractions take place: 'One and a half' $\rightarrow$ 'One plus :r divided by 2' and 'One and a half' $\rightarrow$ ':r plus half' (of :r).

\subsection{Analysis from the TDS Perspective}

\subsubsection{The Economy of the Learning Situation from the TDS Perspective}

In a learning situation, TDS stresses the need to analyse if 'milieu' actually justifies the use of knowledge objectively to solve a given problem. The conditions for this include: (a) the mathematical knowledge aimed at should be the only good method of solving the problem, (b) students should be able to start working with inadequate 'basic knowledge', (c) students should be able to tell for themselves whether their attempts are successful or not, (d) the feedback should not indicate the solution, but it should be suggestive of ways to improve strategies, (e) students should be able to make a rapid series of attempts, but anticipation should be favored (Brousseau 1997).

Considering the example with Turtleworlds, we can see that these conditions are important for the success of the situation. Students have to start with inadequate conceptualisation and the multiplicative functional relation has to be the only good method for completing adequately the construction. Dragging on the slider of the variation tool should allow them to realize by themselves whether their attempts succeeded or failed. The graphical distortion produced by additive relation should also bring suggestive information about the inappropriateness of this solution. Expressing the relation into the Logo procedure should favor anticipation. It seems that the constructionist researcher implicitly built his analysis upon an idea of a milieu providing this kind of interaction. But, since no a priori analysis ensures that the conditions exposed above will actually hold, a TDS researcher would express concerns about the reproducibility of the situation. Did the phenomena observed appear by chance, or would a replication of the implementation be necessarily successful? What are the conditions of success?

Moreover, in the TDS perspective, adidacticity should be preserved. Thus, the teacher, or any person knowing a solution, should not act as to induce students towards this solution. The episode in which the researcher intervenes so as to move students' attention on the multiplicative dependence would then be interpreted by TDS as a too direct indication towards a solution (a "Topaze 
effect", Brousseau 1997, p. 25). In the TDS tradition, it could be noted that, by chance, the students do not follow the intervention and keep exploring addition based relationships. From this point of view, one would also wonder why this intervention was necessary.

Another concern is that Constructionism takes care of 'meanings' rather than directly of 'mathematical knowledge'. The effect of students' interaction with the 'milieu' is described in terms of construction of meanings. Furthermore, as shown in the presentation of the task, Constructionism favours situations where students can appreciate the utility of mathematical ideas. This means that the 'milieu' should not only favor the emergence of meaning and of symbolic components, but also help students appreciate their utility beyond the boundaries of school mathematics. In contrast, TDS considers that 'knowing' (connaissances) built in the interaction is not a goal in itself, but has to be put in correspondence with 'standard' knowledge (savoir) through a process of institutionalization organized by the teacher. Here, the knowledge at stake is a concern because the constructionist analysis tends to stick to a level of understanding by the students not going beyond the situation. Thus, knowledge (savoir) about functions is not clearly identified and remains undistinguished from knowledge about proportionality.

\subsubsection{The Process of Conceptualisation from the TDS Perspective}

According to the typology of activities for function, the physical system here is a path of the turtle in three segments with a given angle between them. In phase 1, the path is fixed with given length of the segments. In phase 2 it depends on two variables and in the next phases, the challenge is to program the path in order that it depends on one variable while conforming to the goal that it represents the letter $\mathrm{N}$. At the level of magnitudes, angles and lengths are involved. What is at stake is formulating a dependency between the length of the vertical segments and the length of the slanted segment in a functional form allowing its expression in a Logo procedure. At the level of functions, the dependency between the 'vertical' and the 'slanted' length is mathematically a multiplicative function, whose coefficient depends on the given angle. 
In phases 1 to 5, while activating the sliders and working on the Logo procedure, the students consider together the physical system and the dependency between magnitudes. Their task is actually to understand the constraints of the physical system as a dependency linking two magnitudes and to find an expression for this dependency in order to write the procedure using a single variable. This implies to choose one length as an independent variable and the other as a dependent variable before building a suitable algebraic expression. In phase 6 , the students move to mathematical functions. Taking the functional expression of the dependency for one angle into account, they understand that the same multiplicative model holds for other angles. Their task is then to find the multiplicative coefficient for each angle. Additional tasks could deal with comparing the functions for different angles by using tables or graphs, thus engaging students in further exploratory activity at this level of functions.

The typology of algebraic activity is based on an epistemology of functions. The distinction between the three levels of activity helps here to analyse the progression of functional meanings, showing the importance of working with magnitudes as a bridge between sensual experience and mathematical functions and suggesting further tasks. What is not clear here is first how the three levels are distinguished in the settings provided by Turtleworlds, and second what are the functional relationships involved in the Logo procedure and to what extent they can serve as preparation for an algebraic understanding of functions.

Actually, there is no one to one correspondence between the three levels of activity and the three components of Turtleworlds. Activity in the three components is principally about measurements. As a difference for instance with Dynamic Geometry, the figure cannot be directly manipulated but only by way of sliders (of the variation tool) that act on measures. The student is then directly placed in a world of measures. The Logo procedures can be viewed as functions with a certain syntax. However, the procedures do not express the functional relationship between lengths which is at stake, but rather a function whose input is a length and the output the figure itself. The actual expression of the functional relationship at stake is within the procedure, embedded in commands for the turtle and thus it is not easily perceived by the user. This is consistent with the remark above that further tasks should lead to consider well identified functions with 
plain definitions, formulas, graphs and table. Again, it can be raised here the need to link the knowledge emerging in interaction with Turtlewords to the standard mathematical knowledge.

\section{Casyopée study}

The session analysed here is part of a series of experimental sessions carried out in the frame of the ReMath project (mentioned before) during the French team's experiment of its own digital artifact, namely Casyopée. As we will see below, the design of Casyopée brings innovative functionalities in order that students understand key actions in the process of modeling a geometrical dependency into an algebraic function. One of these key actions at stake here is the choice of an adequate independent variable, corresponding to a specific functionality (button) in the software. The aim of the study was to evaluate how students could appropriate this functionality, as well as other functionalities encountered in the preceding sessions, and the impact of this progress on their understanding of functions. The study was designed in the TDS tradition, by establishing a supposedly adequate milieu, doing an a priori analysis to support this assumption of adequacy, and an a posteriori analysis to confront the assumption with reality. In these analyses, the two dimensions identified above - the process of conceptualisation and the economy of the learning situation - interact. We distinguished these dimensions in the a posteriori analysis in order to proceed to further integrative steps subsequently.

\subsection{Software}

Casyopée deals with various representations of functions. It provides a symbolic window (Fig. 3) with tools to work with functions in the three registers: numeric, graphic and symbolic. Casyopée also includes a dynamic geometry window (Fig. 4) linked to the symbolic window. The geometric window allows defining independent magnitudes (implying free points) and also dependant ones that can be expressions involving distances, $x$-coordinates or $y$-coordinates. Couples of magnitudes that are in functional dependency can be exported to the symbolic window and define a function, likely to be treated with all the available tools; this can be done automatically, a functionality that was expected to help students in modeling dependencies, and that we will refer to as "automatic modeling" below. 
Casyopée's design is then consistent with the three levels of the typology of activities about functions. It is also conceived to help students in the various algebraic activities. Especially, parameters can be animated via sliders and used formally in calculations; this feature was intended to promote generalisation, a key dimension in global/meta-level algebraic activities.

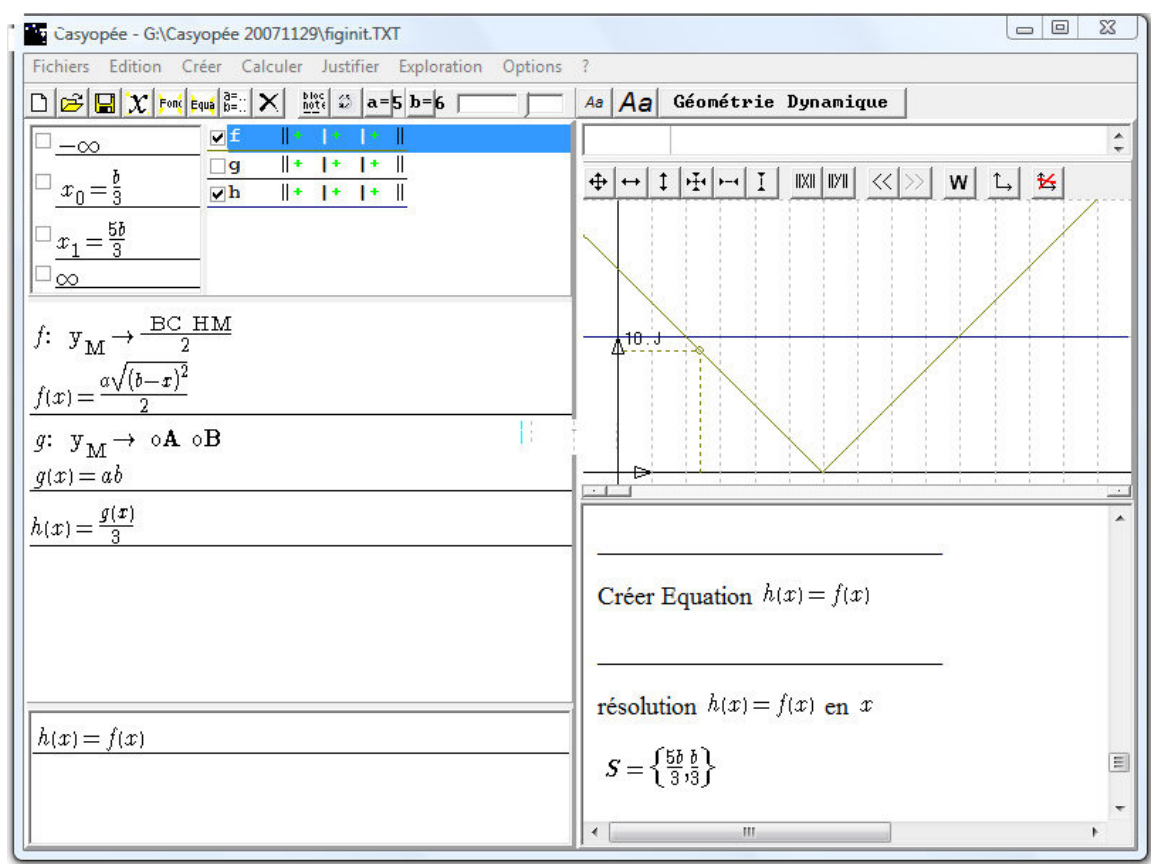

Fig. 3. Casyopée: The symbolic window and the graphic tab.

\subsection{The Design of a Session}

The classroom session analysed here followed three sessions in which students got familiar with the symbolic window, and one in which they were introduced to the dynamic geometry window and to problems about areas. In addition to TDS, the design of the session was also inspired by the typology of activities about functions outlined in Section 2.2. The knowledge at stake is at the boundary between activities at the level of magnitudes and activities at the level of one variable functions. A series of tasks was conceived in which the students had to make a choice of the independent variable as a key step to get an algebraic model of a geometric dependency, in order to solve a problem related to areas. This choice was based on the assumption that it brings to the foreground a key component of the notion of function and also exploits an important feature in the software that students should learn. 
The problem was the following: $A B C D$ being a rectangle, what can be the position of a point $M$ in the plane in order that the area of the triangle $B M C$ is one third of the area of rectangle $A B C D$ (Fig. 4)?

The sides of rectangle were parametric $(A D=a$ and $A B=\mathrm{b})$ in order to ensure generality and a discussion on the fact that the solution does not depend on $a$. The solution is that the points satisfying the condition belongs to one of two straight lines parallel to $B C$ crossing the line $A B$ respectively in $M_{0}$ and $M_{1}$ such that $B M_{0}=B M_{1}=2 A B / 3=2 b / 3$. It is possible to reach this solution geometrically, but the way the problem was proposed to students (in coordinate geometry) and their lack of knowledge in geometry, oriented towards using a function as a model of the variable area. Five successive tasks were then proposed to the students: (Task 1) Build the figure in the dynamic geometry window, $M$ being a free point in the plane (Task 2) Create a geometric calculation for the area of $A B C D$, and moving $M$, conjecture positions of $M$ for which the area of $B M C$ is one third of the area of the rectangle (Task 3) Choose an adequate independent variable to get a model of the geometric function of the area of BMC (Task 4) Use Casyopée's “automatic modeling" to get the definition of a function in the algebraic window (Task 5) Use the algebraic window to get algebraic solutions, and then interpret them in the dynamic geometry window.

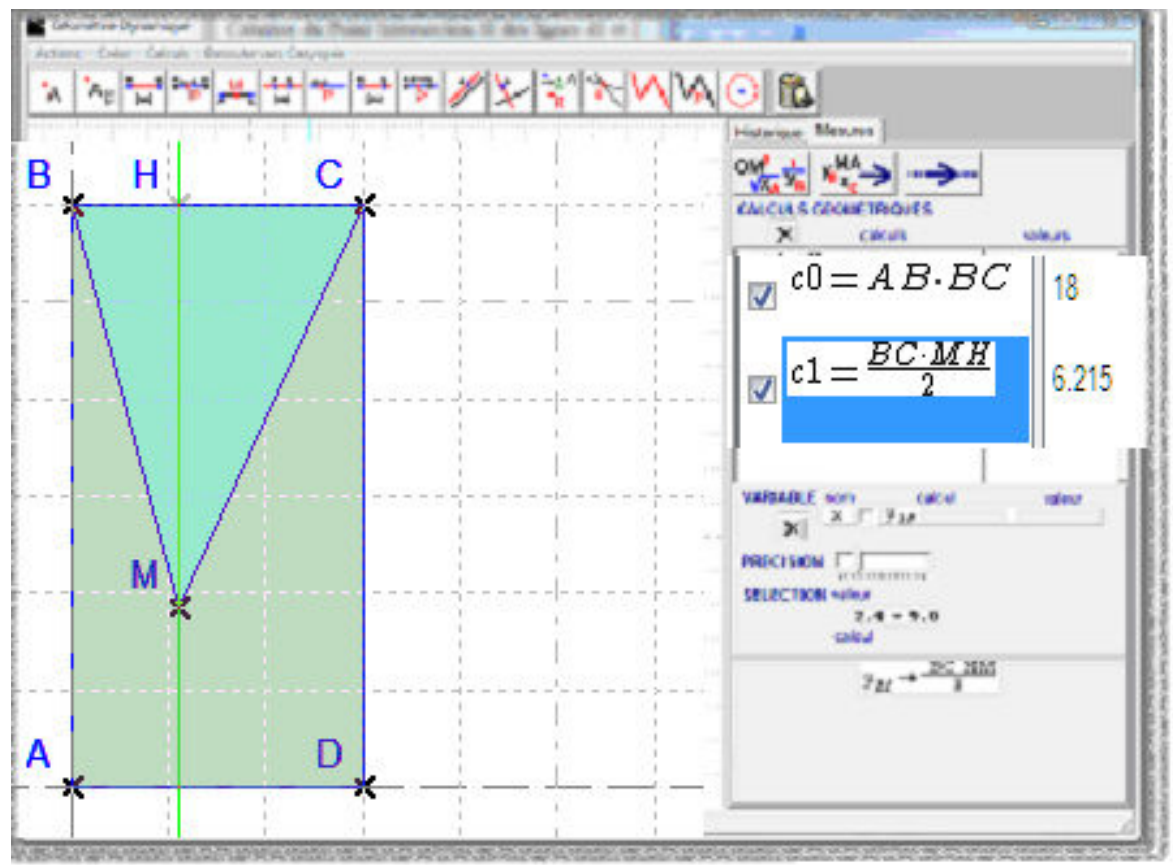

Fig. 4. Casyopée: The dynamic geometrical window and the geometric calculation tab. 
Task 3 was central in the session. It was expected that through this task students could identify precisely the role and mathematical statute of elements involved in modeling a dependency, especially the independent variable, but also algebraic elements already encountered in the previous sessions, like the parameters. Instructions were given in order that the side $A B$ was parallel to the $y$ axis, and the side $B C$ to the $x$ axis. So the students had the choice to select for independent variable some length involving the point $M$ or coordinates of $M$, but only calculations depending univocally of the $y$ coordinate of $M$ could be adequate variables. In particular, it was expected that students would observe that moving horizontally the point $M$ does not change the area, and connect this observation with the fact that $x_{M}$ is not an adequate independent variable. After a user selects an independent and a dependent variable, Casyopée gives some feedback on whether it is possible to create a function with these data. Together with the observation of values of the variables when moving point $M$, this feedback was expected to create a milieu helping students understand the statute of variables in a function modeling a dependency.

The problem solving session lasted 90 minutes and took place in the computer lab with students working alone or in pairs. In the TDS vocabulary, "action" is the main feature of this session. A written assignment that was required for the next week aimed at developing "formulation", another dimension of a "didactical situation".

\subsection{A Priori Analysis}

In task 3 , if a student chooses a length like $B C$ that doesn't vary when $M$ is moved, Casyopée's answer is that it doesn't depend on any free point and no function can be created with this length as an independent variable. Lengths involving $M$ cannot be chosen as independent variables because they depend on the two coordinates. $x_{M}$ can be an independent variable, but, as mentioned above, a change of $x_{M}$ does not affect the value of the area of the rectangle. The version of Casyopée, still in development at that time, calculated a formula involving $y_{M}$, but after that refused to create a function. $y_{M}$ is a suitable variable. The function 
calculated by Casyopée is $x \rightarrow a \times \frac{\sqrt{(x-b)^{2}}}{2}$. It was expected that the identifier $x$ for the independent variable could be confusing for students. Casyopée offers other identifiers, but it was not likely that students will use this feature. In the preceding session, the independent variable was a length on the $y$ axis, and the teacher insisted that this length could be labelled $x$ in the function. After creating the function, the students could work in the familiar symbolic window to solve an equation. If $y_{M}$ has been chosen as a variable, the equation is $\frac{a \times|x-b|}{2}=\frac{a \times b}{3}$ but it can be different if the student chooses another variable; for instance, $y_{B}-y_{M}$ is a possible choice and the equation is then $\frac{a \times|x|}{2}=\frac{a \times b}{3}$. The only difficulty in this equation is the absolute value, that was displayed by Casyopée in the nonsimplified form of $\frac{\sqrt{(x-b)^{2}}}{2}$. Students had no direct technique to solve it by hand, and might be surprised that Casyopée gives two solutions. After that they had to interpret the two solutions in $x$ as two values of $y_{M}$ and to give the geometric solution. It was expected that some technical help from the teacher or researchers observing the session could be necessary, especially with new capabilities of Casyopée, nevertheless preserving the adidactical interaction.

\subsection{Observation}

\subsubsection{Data}

The situation has been implemented in two classes with 25 17-year-old students each one. The implementation took place in a 90-minute session in each class. The teachers of these classes belonged to the ReMath team. Because our interest was on the interaction with Casyopée as an element of the milieu, we choose to have a close observation of a set of students in each class selected with the teachers. Data consisted of recordings of students' work via screen capture software and observers' field notes and students' written assignment. Here we refer to the work of one class. The work of a pair (Elina and Chloé) in this class will be analysed first. Then, in order to provide an a posterirori analysis consistent 
with the TDS perspective, we report briefly on the work of the other students in the same class.

\subsubsection{The Work of Elina and Chloé}

5.4.2.1 The Session Twenty minutes were necessary for the students to build the rectangle, create a geometric calculation for the area of rectangle and create a free point $M$. The given problem asked for a free point in the plane. This was important for the situation, but the pair hesitated, creating first a free point in the plane, then, after a dialog, deleting and creating $M$ on a vertical side $A B$. The students then explored the figure, by moving $M$ on $A B$ during $10 \mathrm{~min}$. They found a solution, by evaluating numerically this area (considering the numerical values of the parameters $a$ and $b$ ) without taking numerical information of the software. They commented "This is good, this is one third of $A B$ " and wrote their solution.

The teacher saw that crucial elements of the milieu had been overlooked: $M$ was not a free point on the plane and no calculation for the area of $M B C$ had been created. He prompted the students to correct. During another ten minutes, the students explored the figure, again looking for a single position of $M$, but now on $B C$ 's perpendicular bisector and not using values of the area of $M B C$ calculated by Casyopée.

Then Elina thought that they could create a function, but Chloé stressed that an independent variable had to be chosen first. Thus they returned to the text of the given problem and tried to identify the requested variables. Reading the message after trying the constant measure $A B$, they moved $M$ to this segment. Trying $B M$, Chloé commented: "here we cannot create the variable". After that, they tried $x_{B}-x_{M}$ and $y_{B}-y_{M}$, reading the message (Casyopée says "the variable depends on $M$, it is defined over ]-infinity, +infinity[") but not creating the variable.

At $50 \mathrm{~min}$, the teacher told them to choose a variable and they chose $x_{M}$. Then they defined the function: $x_{M} \rightarrow A B \times B C$ and got a function $x \rightarrow a \times b$ in the symbolic window. After that, they defined the function $x_{M} \rightarrow \frac{M H \times B C}{2}$. As indicated in the a priori analysis, Casyopée calculated a formula involving $y_{M}$, but after that, refused to create a function. 
At $65 \mathrm{~min}$, they had to recreate the figure because of a technical problem and Chloé realized that the triangle area was constant and equal to one third of the rectangle area for every position of $M$ on a certain horizontal line. They commented "it is always one third ... then the $y$-coordinate is what is important". Surprisingly, again they chose the variable $x_{M}$ and got the same feedback as before.

At 70min, the teacher told them to test the variable $y_{M}$ as indicated in the text of the problem. Casyopée indicated "]-infinity, +infinity[" for the domain. They were not happy and tried to find a way to redefine this domain into[0,3]. Giving up, they defined the function by way of "automatic modeling" and it was accepted by Casyopée. They tried a graphical resolution, but they were confused by the graphical window and needed to get help by the teacher. He showed them how Casyopée offers a dynamic link between a trace on the graph and the free point from which the function is built. The students observed that when they moved $M$ horizontally in the geometry window, the trace did not move (Fig. 3, on the right).

In the last five minutes, they started a report, indicating the functions created and mentioning that when $x_{M}$ changes, the area remains constant and equal to $b$. Note that the area of $B M C$ in the solution equals actually $\frac{a b}{3}$. The students replaced the parameter $a$ (but not $b$ ) by its current value.

5.4.2.2 The Written Assignment Elina and Chloé's report was divided in two parts:

Dynamic geometry They mention that they assign values $(a=3, b=6)$ to the parameters and then they explain how they calculated the areas with the values assigned. They describe their exploration: "in our case, the area of $B M C$ must be 6. Thus we move $M$ in order that the value displayed is 6 . We see that there are two positions of $M$ and only the $y$-coordinate has an influence on the area, the $x$ coordinate does not change the area". 
Casyopée (i.e. the symbolic window They write: "we chose the variable $x_{M}$ "3.

And then "we draw the functions $y_{M} \rightarrow A B \times B C$ and $y_{M} \rightarrow \frac{M H \times B C}{2}$ ", copying the formula given by Casyopée and not mentioning the domain. They copy also the equation and the two solutions. They conclude: "To satisfy the condition, the $y$-coordinate of $M$ should be $y_{M}=\frac{5 b}{3}$ or $y_{M}=\frac{b}{3}$ ". About the difficulties encountered, the students mention: "Finding that only $y$ has an influence on the area of $B M C$, and then choosing $y_{M}$ as an independent variable".

\subsubsection{Other Students}

Among other students, difficulties appeared with the notion of area of a triangle, some just multiplying two sides, or being unable to construct the altitude that was necessary for the calculation. Exploring the variations of the area by moving $M$, half of the students limited the positioning of $M$, like Chloé and Elina, inside the rectangle. They had also difficulties with independent variables. Only one in two students created functions in the first $60 \mathrm{~min}$. There was a variety of choices of independent variable: some students chose $y_{M}$ while others chose an expression like $y_{M}-y_{H}, M H$ being an altitude in the triangle $B M C$. Some written reports show how Casyopée helped to choose an independent variable. For instance, a pair of students wrote: "after several attempts with different choices of variables, we noticed that only the variable $y_{M}$ gave us a result". The reports mentioning this choice generally do not make the connection with the finding of the solutions on two horizontal lines. Some reports do not mention this choice, writing the algebraic solution with the variable $x$, not mentioning what this $x$ represents.

${ }^{3}$ Actually, $x_{M}$ was the label of the button allowing choosing a variable, which explains why the students mention this label, while being aware of $y_{M}$ being the right choice. This label, very confusing, has been changed in further versions of Casyopée. The design decision at the time of this experiment was to implement key actions at Casyopée's interface by way of buttons like in Dynamic Geometry. The difficulty was to find icons that could accurately represent the nature of the action. 


\subsection{A Posteriori Analysis}

\subsubsection{The Economy of the Learning Situation from the TDS Perspective}

The situation was certainly productive in the sense that students could grasp the necessity of choosing an adequate independent variable in order that Casyopée will be able to express a function, but they were far from giving an algebraic signification relatively to this necessity and to the other algebraic objects involved, like for instance the parameters. Casyopée's feedback was generally not well understood. Eventually, it conflicted with students' views, for instance relatively to the domain. It happened that the teacher had to intervene to help going forward in the task. He tended to offer more than a technical help to students, steering them towards steps of the solution and then breaking the intended adidacticity. This was also the case in other ReMath Casyopée experiments. Thus, the influence of the provided feedback seems to be less productive than expected as regards the students' attempts to identify key steps in their mathematical work. Relatively to the question at stake of how students could appropriate the choice of the independent variable, as well as other functionalities already encountered in the preceding sessions, and through this appropriation progress in their understanding of functions, the appreciation is then mixed: the milieu highlights actions that students can identify as steps in the solution; then students are 'pushed' towards these actions; however, this does not guarantee that they acquire an appropriate understanding of these actions.

\subsubsection{The Process of Conceptualisation from the TDS Perspective}

With regard to the knowledge at stake in the previous sessions, students stayed unfamiliar with the parameters used to represent a generic case. Most students, like Elina and Chloé, never changed their values and referred to their current values. The geometric exploration was limited, sometimes to a vertical side of the rectangle and for many students, inside the rectangle. Influenced by current problems involving areas, the students looked for a single position as a solution. Eventually some realised that all points on a line satisfy the condition. The written reports generally mention two positions of $M$ whereas two lines could be deduced from the finding that only the $y$-coordinate has an influence on the area. Making sense of the choice of a variable was then not straightforward and achieved by 
most students only after long hesitation. Most students nevertheless realized that "only $y_{M}$ has an influence" and in their written report wrote the correct functions in $y_{M}$. However, like Elina and Chloé, even when they used this function for expressing and solving an equation, they generally could not interpret the solutions relatively to the geometrical situation. The outcome is that students actually explored the functional dependency at the three levels, geometry, magnitudes and algebra, but were not quite aware of interconnections between these levels.

\subsection{Analysis from the Constructionist Perspective}

\subsubsection{The Economy of the Learning Situation from the Constructionist} Perspective

The reported episode reveals students' diverse views of the symbolic forms provided by the tool and difficulties to relate their selection of variables to the concept of function. To analyse this divergence, we will refer to two gaps at the level of design: one has to do with the design of the environment and, in particular, the nature of the provided feedback and the second with the nature of milieu and the teachers' role.

As for the first, the level of design of Casyopée at that time did not provide students with opportunities to take some actions in relation to the provided feedback. Thus, we see that students could not experiment directly with notation in Casyopée. The correct symbolic form in mathematical terms appears as a 'closed' answer pre-supposing in some way students' understanding of the standard algebraic symbolism of functional dependencies. A constructionist view on design should stress that further development of meaning generation can be facilitated if students have at their disposal a manipulable mechanism so as to take further action based on the provided feedback (i.e. to 'do something' with the tool). Learning activity within constructionist computational media very often consists of students' engagement in debugging intentionally designed 'buggy' behaviors of objects. These objects operate as means to challenge productive meaning generation and provoke further interpretations and actions by students. Thus, Constructionism should emphasise the expressiveness of computational environments as a design principle, i.e. design based on the use of dynamic 
representations that make algebraic symbols and relationships more concrete and meaningful for the students through the ability to express mathematical ideas possibly in ways that may diverge from standard mathematics (see for example the idea of autoexpression which privileges the role of a programming language as a mechanism to control objects by expressing explicitly the relationships between them, Noss et al. 1997).

The second point has to do with the role of the teacher. In TDS there is a strong element of control in students' activity which allows for restricted place for the unexpected. In the episode we can see that the teacher seems to be reluctant to intervene and does it only when he realizes that the students face strong problems in coping with the provided functionalities and integrating them in their activity. In a constructionist perspective, in contrast, teacher's interactions are more participatory from the teachers' side and more strategic in encouraging students to elaborate emergent ideas and generalisations (Kynigos 2012).

\subsubsection{The Process of Conceptualisation from the Constructionist Perspective}

The layers of meanings for function here involve (a) modeling the dependency between $M$ and the area involving this point in order to be satisfied the corresponding relationship, (b) conceptualising the idea of independent variable representing a geometrical object, (c) conceptualising functional dependencies between geometrical objects, (d) abstracting these dependencies at the algebraic level through interpretation of the provided symbolic forms and making of links with standard mathematical symbolism for functions (i.e. functions through "automatic modeling" and mathematical functions in the curriculum). Here we will concentrate on the layers (b) and (d) mentioned above where meaning generation is indicated by students' engagement in building a function for describing the covariation between $y_{M}$ (as an independent variable) and the area of the triangle $B M C$ but faced difficulties to connect their emergent generalisations based on the symbolisation of Casyopée to standard mathematics.

This is a very critical point that forces us to consider the issue of meaning and its role in conceptualisation with an emphasis to the status of the knowledge emerging in students' interaction with the available tools in relation to the targeted 
mathematical knowledge. We see students' difficulty to interpret the two solutions in $x$ as two values of $y_{M}$ as an indication of how the semantics of the software (i.e. the label $x_{M}$ indicating the choice of an independent variable) influences the kind of mathematics which is shaped by the students. Students' answer in the written report reveal that their conceptualisation takes place as an abstract-concrete dialectic indicated by the reference to the label $x_{M}$ ("we chose the variable $x_{M}$ ") and the argumentation around the modelisation of the problem at hand ("To satisfy the condition, the $y$-coordinate of $\mathrm{M}$ should be $y_{M}=\frac{5 b}{3}$ or $y_{M}=\frac{b}{3}$ "). From a situated abstraction perspective, progress in conceptualisation of function can be continued dynamically through reshaping of meanings indicated by shifts in attention evoked, for instance, by new objects emerging in students' activity or by direct teacher's intervention. Under this perspective meaning generation allows recognition of fallibility in the status of students' articulations (e.g., arguments, solutions, noticing feedback, use of representations) emerging through their interaction with the available tools, i.e. these articulations can be considered as evolving and not as complete statements expressed to be confirmed or dismissed. This view allows addressing construction of mathematical knowledge as thinkingin-progress consisted of meanings in formation attached to abstraction processes taking into account the specificity of situations and the contingency of mathematical expression on specific tools in their contexts of use.

\section{Coordinating Constructionist and TDS Analyses}

In this section, we position the concerns/issues raised through the double analysis of the Turtleworlds and Casyopée studies above. The titles of the subsections here are the ones we used to structure the description of the existing research (Sections 2.4 and 2.5) and they are also consistent with the two dimensions of double analysis. We point out what can be learned from this double analysis as regards the economy of the learning situations as well as the processes of conceptualisation of the notion of function with computer environments. 


\subsection{The Economy of Learning Situations}

The motivations underlying the Turtleworlds study build on two opportunities for students' action on functions identified in the respective literature: the dynamic exploration of covariations in geometrical settings and the use of a programming language (see Section 2.4). The constructionist analysis sees there a potential for identifying a mutual dependence between two comparable quantities (interdependency) and also a potential for distinguishing certain kinds of dependence (e.g., additive, multiplicative) between two comparable quantities and the construction of expressions of these by way of Logo code. Implicitly, a 'milieu' is considered here, providing affordances for interaction consistent with the knowledge or meaning at stake. Feedback of the milieu consists in visualizations of correct dynamic figures as well as of failures and mistakes. The various representations and the possibility of actions on these representations are seen as establishing a 'rich' milieu, offering multiple opportunities for meaning generation. The possibility of cognitive conflicts is evoked relatively to the proportional relationship, but with regard to the idea of dependency and expression of functional relations, the constructionist analysis seems to expect that they will emerge 'naturally' in students' conceptualisation as a result of interaction with the milieu and of a dialogue with the teacher.

The TDS analysis of the Turtleworlds study stressed that the milieu here is a zone of free interaction, and meaning is created through the interaction itself, finalized by a construction, rather than by success in a task. The constructionist analysis is supported by an observation of a productive students' work, but no a priori and a posteriori analyses discussed the conditions of this productivity and then, from the TDS point of view, the reproducibility of the situation is questionable. In some sense, the constructionist approach can be characterized as 'serendipitous': it is confident that in a 'rich' situation, emergent phenomena can be interpreted as a creation and reshaping of meanings by students. However, as the TDS analysis points out, what these meanings actually refer to in terms of functions and proportionality remain uncertain.

The motivations underlying the Casyopée study meet at a general level those involved for the use of multirepresentational DGS and CAS software identified in the respective literature (see Section 2.4). Its specificity is that it focuses on key 
points of the transition from functions in a DGS to mathematical functions, aiming to facilitate students' access to symbolic forms. The task in the study is to find a solution of a problem. It can be explored in geometrical settings, but can be really achieved only after the transition to functions of one real variable. The milieu is then inspired by TDS, the task being challenging and the transition being conceived as a non obvious step. Feedbacks are prepared in the software in order to ensure that interaction will actually put the aimed knowledge at stake. However, as indicated above the appreciation is mixed: the interaction seems to produce effects in terms of action in the environment, but not to really make sense for the students. The constructionist interpretation points to an important fact: Casyopée is a mathematical tool, and most of the feedback it provides supposes algebraic knowledge, or coordination between geometry and algebra, that is precisely at stake. In this vein, constructionist analysis brings to the fore issues of tool design emphasising the importance of design choices allowing students' meaningful use of the available infrastructure by forging connections between students' action and tool formalism.

The interventions of the teacher are noticeable in both studies. They are seen by Constructionism as participatory and strategic in enhancing students' exploratory activity. In contrast, TDS cares for adidacticity that could be broken in these interventions, by way of 'Topaze' effects. However, in the Casyopée study, it happens that total adidacticity would have led the students to an impasse.

Constructionist and TDS analyses of learning situations in part converge when they consider a milieu and in part diverge because they have different conceptions of this milieu. Beyond the concepts involved, the style of analysis is also different. TDS analysis is oriented towards evaluating the reproducibility of situations of learning aiming a given knowledge, and constructionist analysis towards identifying occurrences of progression of meaning. Data collected during both studies are consistent with the style of the original framework: record of the interactions in groups of students with a possible participation of the teacher for Constructionism, evidence of procedures consistent with the a priori analysis for TDS. In spite of this, it has been possible to apply an 'alien' analysis to each study, and to identify features related to the economy of the learning situations. This 'double analysis' is clearly deeper and helps to look at the economy of 
learning situations about functions with computers as a particularly complex question. On the one hand, the multiplicity of interconnected representations of functions, of students' possible actions on these, as well as of students' understanding of these representations and actions is an obstacle to the possibility of a controlled milieu, and of adidacticity consistent with TDS. On the other hand, relying exclusively on 'serendipity', and seeing the teacher as an unconstrained participant would allow only weak conclusions relatively to the potential of computer environments. There is then a tension between controlled milieu and adidacticity on one side, and serendipitous learning and teacher's participation on the other side.

\subsection{Conceptualising the Notion of Function with the Help of Computers}

\subsubsection{From Process-Object to Covariation Aspect of Function}

The two studies actually propose situations promoting a covariation view of functions. These situations are based on modeling dynamic phenomena connected with a sensual experience of dependency. The analyses carried out suggest that situations of that kind have a potential to help students reach awareness of covariation by connecting in a meaningful way its different representations. However, the two analyses diverge in how they consider covariation in these situations. The constructionist analysis looks at how covariational meanings are reframed in students' progression at a personal or inter-personal level, independently of standard mathematics. In contrast, the typology inspiring Casyopée refers to covariation between objects defined in standard mathematics (e.g., geometrical figures, measures, algebraic functions) and favours the development and observation of learning trajectory through settings organizing these objects.

The two analyses do not consider the same objects and thus cannot be directly combined. However, the respective review of research suggests that understanding covariation is a long term process and that there is not a simple approach to engage students in this process (see Section 2.5). An analysis based on the typology of algebraic activities can be useful in describing students' passages in different levels of work with covariation in a particular setting (e.g., 
from activities in a physical system to functions of one real variable), while a situated abstraction analysis can be used to focus on the conceptual aspects of this process by addressing the role of external resources in the evolution of mathematical knowledge in this particular setting.

\subsubsection{Understanding the Idea of Independent Variable}

This idea of independent variable was particularly at stake in the Casyopée study. Choosing an adequate independent variable was thought of as a particular action with the software allowing accessing the algebraic part of the typology, and, in the TDS a priori analysis, feedback was supposed to ensure the mathematical productivity of this action. However, things were not so simple. The constructionist analysis identified the resisting concept image, confirming Thompson's intuition (see the reported example in Section 2.5). At the same time, the Turtleworlds study revealed that students were able to make sense of independent variable at the operational level of identifying and expressing functional relations to achieve a particular construction goal (i.e. robust enlargingshrinking geometrical figures) within the respective setting. This can be an indication of the potential of particular forms of representations and connections between them (e.g., exploiting the expressive power of linguistic representations) that can be used to introduce students to independent variable before official instruction of functions of one variable.

\subsubsection{The Role of Symbolism}

It is a distinct design feature of Casyopée and Turtleworlds, and of the associated situations of use, to deal with symbolism, aiming to reconcile symbolic forms and dynamic manipulation of mathematical objects and relationships. In this approach, the graphical and numerical settings are subsidiary means for exploration, which is different from current approaches that tend to strongly rely on these settings for problem solving, drawing on the potentialities of technology for graphing and tabulating functions and justified by students' weaknesses in symbolic manipulation (see for an example, Hoffkamp 2010). The constructionist analysis shows the productivity of the elaboration of symbolic expressions involving measures by way of Logo programming in Turtleworlds, and as a preparation for functions of one variable in Casyopée, via the 'reshaping of meanings'. Transition 
to algebraic forms that Casyopée should favor is again to be thought of as a long term process.

\section{Conclusions}

The general goal of this paper is to explore the potential of computational environments for the teaching and learning of functions by networking Constructionism and TDS. Networking took place at the level of research traditions through double analysis of two research studies carried out in the Greek and the French didactic context respectively. The emphasis given to a milieu in both traditions made double analysis possible and productive. The similar method of collecting detailed observation of students' work also helped, but it is worth noting that, while in the constructionist inspired tradition well chosen observation of particular students' work can be the basis for analysing, the TDS inspired tradition needs to refer also to observation at the level of the classroom in order to tackle reproducibility.

As a direct answer to the general goal of this paper, coordinating the analyses of the two studies (Section 6) in terms of two common dimensions (i.e. 'The economy of learning situations' and 'The process of conceptualising the notion of function'), resulted in a deepened and more balanced understanding of the issues around the potential of computational environments for the teaching and learning of functions. With respect to the economy of learning situations, the double analysis points out a tension between controlled milieu and adidacticity on the one side, and serendipitous learning and teacher participation on the other side. TDS tradition is concerned with reproducibility but, in the experiment presented in this paper, encounters obstacles resulting from limited predictability of the software feedback and its interpretation by students, while the constructionist tradition favours deep insight on the learning process and is more open to exploit often unexpected students' emergent ideas and generalisations. Relatively to the process of conceptualisation, the main tension is between standard knowledge and meanings. For one tradition, access to the understanding of covariation of functional ideas like the notion of independent variable and of the symbolism, is through learning trajectories involving activities on standard mathematical objects, while the other tradition allows for process of conceptualisation more distant from standard mathematics. These tensions are inherent in the complexity 
of the computer environments that Turtleworlds and Casyopée represent, as well as in the notions involved in the field of functions.

At the level of didactical knowledge about functions, the coordinated double analysis (Section 6) indicates algebraic modeling of geometrical dependencies as a fruitful domain for engaging students in functional thinking. It also raises the importance of tool design in facilitating students' productive work with geometrical and algebraic representations. According to the reported examples, students' meaningful transition from the world of covariation to the world of functions of one variable is not at all an easy task. It seems to be a long term process which may be facilitated through particular forms of interconnected representations that can be used to introduce algebraic ideas to the students, possibly before formal instruction of one variable functions.

Overall, the synthesis of the results leads to a more complete view of the potential of digital technologies for the learning of functions from the two perspectives. We summarise the main issues around this potential as indicated by the findings of this study: (a) The importance of providing students with opportunities to act on/experiment with integrated representations of functions linking geometry and algebra, (b) The central role of tool design in facilitating the transition from exploration of covariation at the geometrical setting (e.g., by distinguishing different kinds of dependence, by noticing failures and mistakes through appropriate feedback) to the symbolic forms of functions (e.g., through tools allowing symbolic expression of functional relations), (c) The need to take a balanced view on students' construction of knowledge for functions by addressing epistemological aspects (e.g., its relation to the standard knowledge) as well as cognitive aspects (e.g., its formation as thinking-in-progress tied-up within the available tools and their specific context of use), (d) The role of the teacher as a critical element of task design and the evolution of students' activity in order to achieve the intended learning aims.

The insight provided by the above findings is not limited to the particular episodes from the classroom. It indicates an advance at the level of the two theories since it highlights their underlying theoretical claims and assumptions. As an example, see how the duality between the knowledge built by interacting with the milieu ('knowing') to the standard mathematical knowledge at stake ('knowledge') 
raised by TDS can be understood in terms of construction of meanings. In this case, knowing (connaissances) can be seen as relative to meaning generation since both terms address formation of knowledge emerging in students' interactions with the use of the available tools. Since constructionist approaches do not prescribe an institutionalization process, meaning generation indicates a 'bridge' between knowing and knowledge in the sense that it emphasises the potential of meanings to lead to more formal understandings.

As an agenda beyond the networking of the two traditions, we now reflect on the research benefits for each of the approaches in the present study. Overall, double analyses helped us broaden our views in reflecting on our own research approach. The application of TDS and constructionist theoretical tools to the same research study has allowed us to better articulate the affordances and constrains of each approach in understanding the data. We take the example of the Turtleworlds study. The 'alien' analysis by TDS stressed the relation between meaning and standard knowledge. This may led to the emergence of new research questions for this study. For instance, one research question of the Turtleworlds study was the following: "How do students use the available representations in Turtleworlds to construct meanings for proportional relations when engaged in enlargingshrinking geometrical figures?". Taking into account the above challenge provided by the TDS perspective, this question can be complemented by a second one: "Are these meanings linked to the standard knowledge for proportional relations and how?". This confirms that the complementary use of different principles of the two theories can support a more complete view/analysis of particular learning situations.

As an overall conclusion, we do believe that research attempts aiming to address the potential of computational environments for the teaching and learning of mathematics may benefit from the present study both at the level of proposing networking processes between different research traditions as well as at the level of operationalizing networking tools and methods to articulate connections between different traditions through close research collaboration. 


\section{References}

Artigue, M. (1997). Le logiciel DERIVE comme révélateur de phénomènes didactiques liés à l'utilisation d'environnements informatiques pour l'apprentissage. Educational Studies in Mathematics, 33, 133-169.

Artigue, M. (Ed.) (2009). Integrated theoretical framework (Version C). 'ReMath' (Representing Mathematics with Digital Media) FP6, IST-4 026751 (2005-2009). Del. 18. Retrieved September 21, 2012, from http://remath.cti.gr.

Artigue, M. \& Bardini, C. (2010). New didactical phenomena prompted by TI-nspire specificities - the mathematical component of the instrumentation process. In V. DurandGuerrier, S. Soury-Lavergne \& F. Arzarello (Eds.), Proceedings of the 6th Congress of the European Society for Research in Mathematics Education (pp. 19-28). Lyon, France.

Bikner-Ahsbahs, A., \& Prediger, S. (2010). Networking of theories - an approach for exploiting the diversity of theoretical approaches. In B. Sriraman \& L. English (Eds.), Theories of mathematics education: Seeking new frontiers (pp. 483-506). New York: Springer.

Bloch, I. (2003). Teaching functions in a graphic milieu: what forms of knowledge enable students to conjecture and prove? Educational Studies in Mathematics, 52, 3-28.

Breidenbach, D., Dubinsky, E., Hawks, J., \& Nichols, D. (1992). Development of the process conception of function. Educational Studies in Mathematics, 23, 247-285.

Brousseau, G. (1997). The theory of didactic situations in mathematics. Dordrecht: Kluwer Academic Publishers.

Carlson, M., Jacobs, S., Coe, E., Larsen, S. \& Hsu, E. (2002). Applying covariational reasoning while modeling dynamic events: A framework and a study. Journal for Research in Mathematics Education, 33(5), 352-378.

Confrey, J., \& Smith, E. (1995). Splitting, covariation, and their role in the development of exponential functions. Journal for Research in Mathematics Education, 26, 66-86.

Doorman, M., Drijvers, P., Gravemeijer, K., Boon, P. \& Reed, H. (2012). Tool use and the development of function concept: From repeated calculations to functional thinking. International Journal of Science and Mathematics Education, 10, 1243-1276.

Drijvers, P., Godino, J. D., Font, V. \& Trouche, L. (2013). One episode, two lenses. A reflective analysis of student learning with computer algebra from instrumental and onto-semiotic perspectives. Educational Studies in Mathematics, 82, 23-49.

Dubinsky, E. (1999). One theoretical perspective in undergraduate mathematics education research. In O. Zaslavsky (Ed.), Proceedings of the 23rd Conference of the International Group for the Psychology of Mathematics Education (Vol. 4, pp. 65-73). Haifa, Israel.

Duval, R. (2000). Basic issues for research in mathematics education. In T. Nakahara, \& M. Koyama (Eds.), Proceedings of the 24th Conference of the International Group for the Psychology of Mathematics Education (Vol. 1, pp. 55-69). Hiroshima University.

Falcade, R., Laborde, C., \& Mariotti, M. A. (2007). Approaching functions: Cabri tools as instruments of semiotic mediation. Educational Studies in Mathematics, 66(3), 317-333. 
Harel, I. \& Papert, S. (Eds.) (1991). Constructionism: Research reports and essays. Norwood, NJ: Ablex Publishing Corporation.

Hazzan, O., \& Goldenberg, E. P. (1997). Student's understanding of the notion of function. International Journal of Computers for Mathematical Learning, 1(3), 263-290.

Hoffkamp, A. (2010). Enhancing functional thinking using the computer for representational transfer. In V. Durand-Guerrier, S. Soury-Lavergne \& F. Arzarello (Eds.), Proceedings of the 6th Congress of the European Society for Research in Mathematics Education (pp. 12011210). Lyon, France.

Hohenwarter, M., \& Fuchs, K. (2005). Combination of dynamic geometry, algebra and calculus in the software system GeoGebra. In C. Sárvári (Ed.), Proceedings of Computer Algebra Systems and Dynamic Geometry Systems in Mathematics Teaching (pp. 128-133). Pecs, Hungary: University of Pecs.

Hoyles C., Lagrange, J-B. \& Noss, R. (2006). Developing and evaluating alternative technological infrastructures for learning mathematics. In J. Maasz \& W. Schloeglmann (Eds.), New mathematics education research and practice (pp. 263-312). Rotterdam: Sense Publishers.

Kieran, C. (1992). The learning and teaching of school algebra. In D. A. Grouws (Ed.), Handbook of research on mathematics teaching and learning (pp. 390-419). New York: Macmillan.

Kieran, C. (2007). Learning and teaching algebra at the middle school through college levels. In F. K. Lester Jr. (Ed.) Second handbook of research on mathematics teaching and learning (pp. 707-762). Charlotte, NC: Information Age Publishing; Reston, VA: NCTM.

Kieran, C. \& Yerushalmy, M. (2004). Research on the role of technological environments in algebra learning and teaching. In K. Stacey, H. Shick \& M. Kendal (Eds.), The future of the teaching and learning of algebra. The 12th ICMI (International Commission on Mathematical Instruction) Study. New ICMI Study Series (Vol. 8, pp. 99-152). Kluwer Academic Publishers.

Kieran, C. \& Drijvers, P. (2006). The co-emergence of machine techniques paper-and pencil techniques, and theoretical reflection: a study of CAS use in secondary school algebra. International Journal of Computers for Mathematical Learning, 11, 205-263.

Kynigos, C. (2004). A "black-and-white box" approach to user empowerment with component computing. Interactive Learning Environments, 12(1-2), 27-71.

Kynigos, C. (2012). Constructionism: theory of learning or theory of design? Invited Regular Lecture to the 12th International Congress on Mathematical Education. COEX, Seoul, Korea.

Lagrange, J.-B. (2005). Curriculum, classroom practices, and tool design in the learning of functions through technology-aided experimental approaches. International Journal of Computers for Mathematical Learning, 10, 143-189.

Lagrange, J.-B. \& Artigue, M. (2009). Students' activities about functions at upper secondary level: a grid for designing a digital environment and analysing uses. In M. Tzekaki, M. Kaldrimidou \& C. Sakonidis (Eds.), Proceedings of the 33rd Conference of the International 
Group for the Psychology of Mathematics Education (Vol. 3, pp. 465-472). Thessaloniki, Greece: PME.

Mackrell, K. (2011). Introducing algebra with interactive geometry software. In W.-C. Yang, M. Majewski, T. de Alwis, E. Karakirk, (Eds.), Electronic proceedings of the 16th Asian Technology Conference in Mathematics, (pp. 211-220). Mathematics and Technology, LLC.

Noss, R. (2004). Designing a learnable mathematics: a fundamental role for the computer? Regular Lecture to the 10th International Congress of Mathematics Education (ICMI 10). Roskilde University, Roskilde, Denmark.

Noss, R., \& Hoyles. C. (1996). Windows on mathematical meanings. Kluwer Academic Press.

Noss, R., Healy, L., \& Hoyles, C. (1997). The construction of mathematical meanings: Connecting the visual with the symbolic. Educational Studies in Mathematics, 33(2), 203233.

Oehrtman, M., Carlson, M. \& Thompson, P. (2008). Foundational reasoning abilities that promote coherence in students' function understanding. In M. P. Carlson \& C. Rasmussen (Eds.), Making the connection: Research and teaching in undergraduate mathematics (pp. 27-42). Washington DC: Mathematical Association of America.

Papert, S. (1980). Mindstorms. Children, computers and powerful ideas. N.Y.: Basic Books.

Prediger, S., Bikner-Ahsbahs, A. \& Arzarello, F. (2008). Networking strategies and methods for connecting theoretical approaches: first steps towards a conceptual framework. Zentralblatt für Didaktik der Mathematik, 40, 165-178.

Radford, L. (2005). The semiotics of the schema. Kant, Piaget, and the calculator. In M. H. G. Hoffmann, J. Lenhard \& F. Seeger (Eds.), Activity and sign - Grounding mathematics education. Festschrift for Michael Otte (pp. 137-152). New York: Springer.

Radford, L. (2008). Connecting theories in mathematics education: challenges and possibilities. Zentralblatt für Didaktik der Mathematik, 40, 317-327.

Sfard, A. (1991). On the dual nature of mathematical conceptions: Reflections on processes and objects as different sides of the same coin. Educational Studies in Mathematics, 22, 1-36.

Slavit, D. (1997). An alternate route to the reification of function. Educational Studies in Mathematics, 332, 259-281.

Tall, D. (1996). Functions and calculus. In A. Bishop, K. Clements, C. Keitel, J. Kilpatrick, \& C. Laborde (Eds.), International handbook of mathematics education (pp. 289-325). Dordrecht: Kluwer Academic Publishers.

Tall, D. \& Vinner, S. (1981). Concept image and concept definition in mathematics, with special reference to limits and continuity. Educational Studies in Mathematics, 12, 151-169.

Thomas, M. O. J., Monaghan, J. \& Pierce, R. (2004). Computer algebra systems and algebra: Curriculum, assessment, teaching, and learning. In K. Stacey, H. Chick, \& M. Kendal (Eds.), The teaching and learning of algebra: The 12th ICMI study (pp. 155-186). Norwood, MA: Kluwer Academic Publishers.

Thompson, P. W. (1994). Students, functions, and the undergraduate curriculum. In E. Dubinsky, A. H. Schoenfeld, \& J. J. Kaput (Eds.), Research in collegiate mathematics education, I: 
Issues in mathematics education (Vol. 4, pp. 21-44). Providence, RI: American Mathematical Society.

Van der Kooij, H. (2010). Mathematics at work. In M. M. F. Pinto \& T. F. Kawasaki (Eds.), Proceedings of the 34th Conference of the International Group for the Psychology of Mathematics Education (Vol. 1, 121-124). Belo Horizonte, Brazil: PME.

Weigand, H. G. \& Bichler, E. (2010). Towards a competence model for the use of symbolic calculators in mathematics lessons: the case of functions. Zentralblatt für Didaktik der Mathematik, 42, 697-713. 